\title{
Structures and Corresponding Functions of Five Types of Picornaviral 2A Proteins
}

\begin{abstract}
Xiaoyao Yang ${ }^{1,2,3}$, Anchun Cheng ${ }^{1,2,3 *}$, Mingshu Wang ${ }^{1,2,3 *}$, Renyong Jia ${ }^{1,2,3}$, Kunfeng Sun 1,2,3, Kangcheng Pan ${ }^{2}$, Qiao Yang 1,2,3, Ying Wu 1,2,3, Dekang Zhu', Shun Chen 1,2,3, Mafeng Liu ${ }^{1,2,3}$, Xin-Xin Zhao ${ }^{1,2,3}$ and Xiaoyue Chen ${ }^{2,3}$
\end{abstract}

${ }^{1}$ Institute of Preventive Veterinary Medicine, Sichuan Agricultural University, Chengdu, China, ${ }^{2}$ Key Laboratory of Animal Disease and Human Health of Sichuan Province, Sichuan Agricultural University, Chengdu, China, ${ }^{3}$ Avian Disease Research Center, College of Veterinary Medicine, Sichuan Agricultural University, Chengdu, China

Among the few non-structural proteins encoded by the picornaviral genome, the 2A protein is particularly special, irrespective of structure or function. During the evolution of the Picornaviridae family, the 2A protein has been highly non-conserved. We believe that the $2 \mathrm{~A}$ protein in this family can be classified into at least five distinct types according to previous studies. These five types are (A) chymotrypsin-like 2A, (B) Parechovirus-like 2A, (C) hepatitis-A-virus-like 2A, (D) Aphthovirus-like 2A, and (E) 2A sequence of the genus Cardiovirus. We carried out a phylogenetic analysis and found that there was almost no homology between each type. Subsequently, we aligned the sequences within each type and found that the functional motifs in each type are highly conserved. These different motifs perform different functions. Therefore, in this review, we introduce the structures and functions of these five types of 2As separately. Based on the structures and functions, we provide suggestions to combat picornaviruses. The complexity and diversity of the $2 \mathrm{~A}$ protein has caused great difficulties in functional and antiviral research. In this review, researchers can find useful information on the 2A protein and thus conduct improved antiviral research.

Keywords: 2A protein, five types, non-conserved, structure, function, antiviral research

\section{INTRODUCTION}

According to the ICTV, in March 2017, the family Picornaviridae consisted of 80 species grouped into 35 genera (Adams et al., 2016). The members of Picornaviridae are single-stranded, positivesense RNA viruses. The genome contains a single ORF that encodes a precursor protein that includes the coding region of the capsid protein (P1) and non-structural proteins (P2 and P3).

Abbreviations: AIV, Aichi virus; BGPV, Bluegill picornavirus; BKV, bovine kobuvirus; BRAV, bovine rhinitis A virus; BRBV, bovine rhinitis $\mathrm{B}$ virus; CPV, Carp picornavirus; CV, coxsackievirus; eEF, eukaryotic elongation factor; eIF, eukaryotic initiation factor; EMCV, encephalomyocarditis virus; EPV, Eel picornavirus; ERAV, equine rhinitis A virus; ERBV, equine rhinitis B virus; eRF, eukaryotic release factors; EV, enterovirus; FHMPV, fathead minnow picornavirus; FMDV, foot-andmouth disease virus; F2A, foot-and-mouth disease virus 2A; GFTV, genet fecal theilovirus; HAV, Hepatitis A virus; HPeV, human parechovirus; ICTV, International Committee on Taxonomy of Viruses; IFN, interferon; IL, interleukin; IRES, internal ribosome entry site; LV, Ljungan virus; ML, maximum likelihood; NLS, nuclear localization sequence; NPC, nuclear pore complex; Nups, nucleoporins; ORF, open reading frame; PABP, poly (A)-binding protein; PKV, porcine kobuvirus; PTV-1, porcine teschovirus-1; PV, poliovirus; RV, rhinovirus; SAFV, saffold virus; TAV, thosea asigna virus; TEV, theilovirus; TMEV, Theiler's murine encephalomyelitis virus; VHEV, Vilyuisk human encephalomyelitis virus; $2 \mathrm{~A}^{\mathrm{pro}}, 2 \mathrm{~A}$ protease. 
The precursor is cleaved into the mature proteins by viral proteins that act as proteases. The final structure is generally VP4-VP2-VP3-VP1-2A-2B-2C-3A-3B-3C-3D (Figure 1A). Most of the viruses in this family contain additional unique structural features in their genomes.

It has been reported that there are several types of nonstructural $2 \mathrm{~A}$ proteins. We believe that they can be divided into five types according to their structures and corresponding functions, with little correlation between each type. These types are (A) the chymotrypsin-like 2A, which contains a conserved catalytic triad, (B) the Parechovirus-like 2A, which has a conserved H-NC box, (C) the hepatitis-A-virus-like 2A, which is mainly involved in viral capsid assembly, (D) the Aphthovirus-like 2A, which, along with the first amino acid of $2 \mathrm{~B}$ (P), has a "DxExNPGP" tail at its C-terminus (where ' $\mathrm{x}$ ' is any amino acid), and (E) the $2 \mathrm{~A}$ sequence of the genus Cardiovirus, which contains a DxExNPGP and a "YxxxxL $\Phi$ " (where $\Phi$ is a hydrophobic amino acid) motif. The highly complicated nature of $2 \mathrm{~A}$ proteins has been an important factor hindering research. A comprehensive understanding of these proteins will greatly promote further research and clinical application of the research. In this paper, we focus on the existing reports on the five types of $2 \mathrm{~A}$ to produce a relatively comprehensive review based on their structures and functions. We also provide suggestions for researchers to combat virus replication by targeting the $2 \mathrm{~A}$ proteins.

\section{EVOLUTIONARY ANALYSIS AND SEQUENCE ALIGNMENT OF THE FIVE TYPES OF 2A PROTEINS}

In addition to the hepatitis-A-virus-like $2 \mathrm{~A}$ protein, two $2 \mathrm{~A}$ proteins were selected from each type to build a phylogenetic tree (Figure 2). It can be seen that there are almost no similarities between each type. This suggests that there is no common evolutionary ancestor of the five types of $2 \mathrm{~A}$ sequences. In addition, except for the chymotrypsin-like $2 \mathrm{~A}$ proteins, the bootstrap value within each type is extremely low. Regarding the value for the chymotrypsin-like $2 \mathrm{~A}$ proteins, this may be due to the fact that they function as a result of their overall conformation, so the full sequences are similar. In contrast, the other types of 2A function only due to several amino acids, and the remaining sequence is highly non-conserved. Therefore, we carried out a sequence alignment analysis separately for each type.

It can be seen that the catalytic triad His-Asp-Cys, which represents the active site of chymotrypsin-like $2 \mathrm{~A}$, is highly conserved (Figure 3A). This chymotrypsin-like 2A, which functions as a proteolytic enzyme that cleaves the viral protein precursors and host proteins, can help the virus to evade host immune responses in multiple ways. Many researchers regard it as a key drug target, aiming at its active sites to combat the virus. The H-NC box of Parechovirus-like 2A is also highly conserved (Figure 3B). This $\mathrm{H}-\mathrm{NC}$ box is involved in viral replication and host cell proliferation. The Aphthovirus-like 2A are all short peptides. The DxExNPGP motif appears to be highly conserved in the small number of amino acids that make up these peptides (Figure 3D). This motif induces a co-translation event known as ribosomal "skipping," thus separating the viral protein at the " $\mathrm{q} \downarrow \mathrm{P}$ ” site. Many basic scientific research studies and clinical experiments have used this type of $2 \mathrm{~A}$ peptide as a tool to cleave the precursor protein. In the $2 \mathrm{~A}$ sequences of the genus Cardiovirus, the DxExNPGP and $\operatorname{YxxxxL} \Phi$ motifs are all conserved (Figure 3C). The DxExNPGP motif functions like Aphthovirus-like 2A. The $\operatorname{YxxxxL} \Phi$ motif is a binding site for eukaryotic initiation factor $4 \mathrm{E}$ (eIF4E). No special functional motif has been found for the hepatitis-A-virus-like 2A (Table 1). Due to the distinct nature of each type of $2 \mathrm{~A}$ protein, the subsequent sections of this review elucidate the structural motifs and functions of each type of $2 \mathrm{~A}$ proteins in turn to help researchers to understand the $2 \mathrm{~A}$ proteins of Picornaviridae more clearly.

\section{STRUCTURE AND FUNCTIONS OF CHYMOTRYPSIN-LIKE 2A PROTEASE $\left(2 A^{\text {PRO }}\right)$}

\section{Important Structural Features of Chymotrypsin-Like 2A ${ }^{\text {pro }}$}

In members of Picornaviridae, most of the $2 \mathrm{~A}$ proteins are chymotrypsin-related proteases. Comparing the structures of these $2 \mathrm{~A}$ proteins, it can be shown that their overall conformations are similar (Figure 4). The typical structure of $2 \mathrm{~A}^{\text {pro }}$ contains an $\mathrm{N}$-domain comprising a four-stranded antiparallel $\beta$-sheet and a C-domain comprising a six-stranded antiparallel $\beta$-barrel; these domains are connected via a long interdomain loop (Figure 4A). Two $\beta$-strands form an antiparallel $\beta$-hairpin named the dityrosine flap within the $\mathrm{C}$-domain (Figure 4B). There is an open cleft across the surface of the protein. The residues of the catalytic triad, Cys-His-Asp, are found in the cleft, which has conformational flexibility and thus fits well with the substrates (Cai et al., 2013). In different 2As, the different cleft widths adapt to the different substrates (Figure 4C). For example, $2 \mathrm{~A}^{\text {pro }}$ of Rhinovirus $A$ (RV-A) cannot process the same cleavage sites as $2 \mathrm{~A}^{\text {pro }}$ of Rhinovirus $B$ (Neubauer et al., 2013). Specific residues in $2 A^{\text {pro }}$ can convert the cleft from a "closed" to an "open" state in a reversible manner (Sun et al., 2013). The catalytic site of this type of $2 \mathrm{~A}^{\text {pro }}$ consists of the conserved catalytic triad (Cys-His-Asp). The catalytic site of poliovirus (PV) consists of Cys109-His20-Asp38 (Hellen et al., 1991). The active sites may be different in other viruses, but the overall conformation is maintained (Table 2 and Figure 4D). Cys55, Cys57, Cys15, and His117 in PV 2A pro are critical for maintaining its active conformation and catalytic activity ( $\mathrm{Yu}$ and Lloyd, 1992). A zinc ion is required to maintain the conformation of $2 \mathrm{~A}^{\text {pro }}$. However, when added externally, zinc ions appear to be inhibitory (Maghsoudi et al., 2008). The protease can be inhibited by a potent zinc chelator, but the protease will rapidly gain activity after the addition of excess zinc (Glaser et al., 2003). Despite these conserved features, some $2 \mathrm{~A}^{\text {pro }}$ have distinctive properties. For example, the RV-C2 $2 \mathrm{~A}^{\text {pro }}$ has three short 310 -helices (Lee et al., 


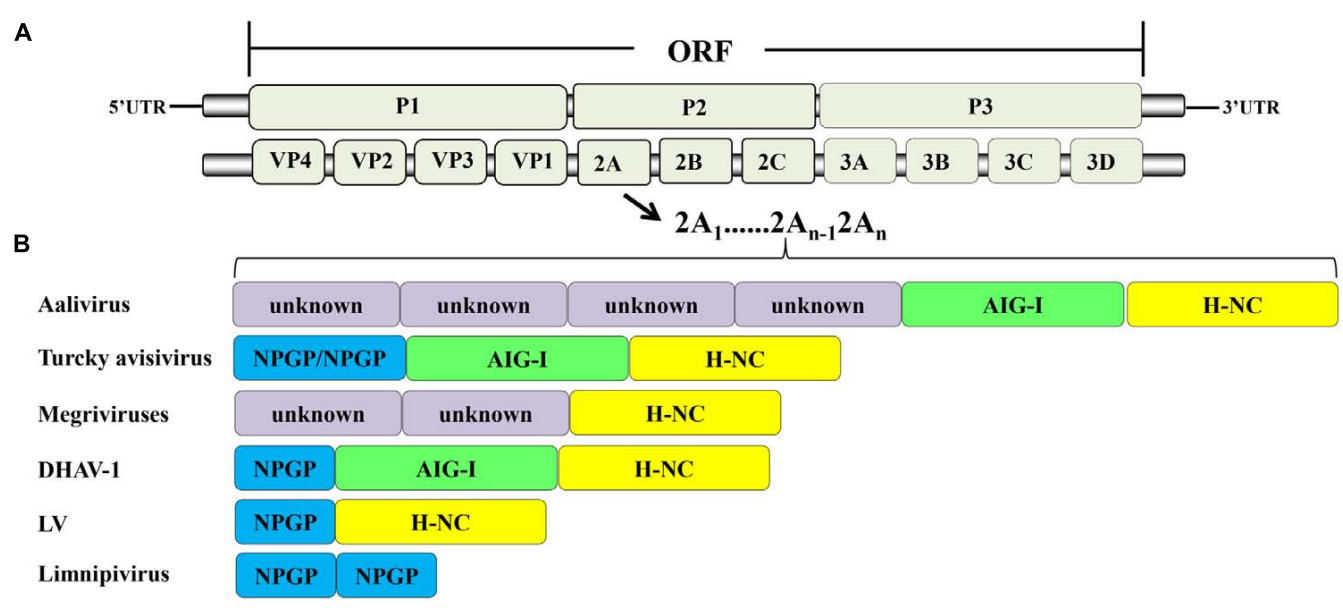

FIGURE 1 | Picornavirus genome structure. (A) Protein processing of picornaviruses. (B) Some viruses have acquired multiple 2A genes, which occur in tandem in their genomes.

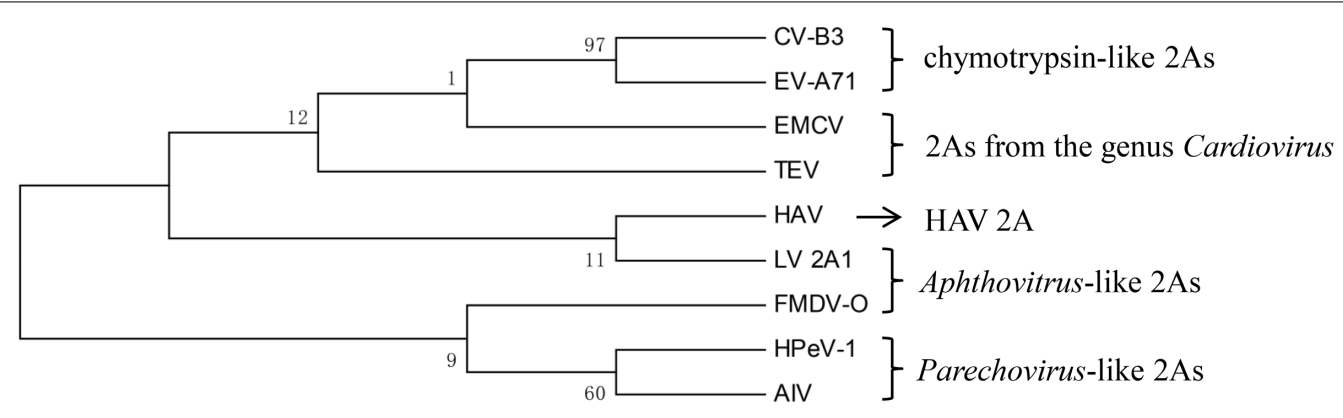

FIGURE 2 | Phylogenetic tree based on the five types of 2A proteins. The tree was constructed using a ML method. The 2As of EV-A71 and CVB3 are chymotrypsin-like 2As. The 2As of HPeV-1 and AIV are Parechovirus-like 2As. The 2A of FMDV and the 2A1 of LV are Aphthovirus-like 2As. The 2As of EMCV and TEV are from the genus Cardiovirus. The numbers at the nodes represent the bootstrap value. (GenBank accession numbers: EV-A71, AAB39968.1; CVB3, AAB02228.1; HPeV-1, ABK54353.1; AIV, NP_740438.1; FMDV-O, ARB66056.1; LV, NP_705877.1; EMCV, NP_740406.1; TEV, NP_740428.1; HAV, ACD74580.1).

2014). A hydrophobic "LLWL" motif followed by an acidic "DEE" motif exists at the C-terminus of EV A71 (EV-A71) 2A pro (Mu et al., 2013).

Several factors can affect the structure of $2 \mathrm{~A}^{\text {pro }}$. Low temperature is necessary for the integrity of CV B3 (CV-B3) $2 \mathrm{~A}^{\text {pro }}$ (Maghsoudi et al., 2008). Elevating the temperature will induce the active site to undergo a change (Maghsoudi et al., 2011). Structure determines function. The recognition of eIF4GI by CVB4 2A $\mathrm{A}^{\text {pro }}$ is driven by the unique surface properties (Baxter et al., 2006), and conformational change of the active site decreases the cleavage of eIF4G (Maghsoudi et al., 2011). The LLWL motif in EV-A71 2A $\mathrm{A}^{\text {pro }}$ is critical for maintaining the conformation and positioning of the following acidic motif (DEE), the correct positioning of which is required for virus replication (Mu et al., 2013).

\section{Function of $2 A^{\text {pro }}$ with Respect to the Virus Itself}

Chymotrypsin-like $2 \mathrm{~A}^{\text {pro }}$ cleaves the viral polyprotein between VP1 and 2A. When a special mutation was introduced between VP1 and $2 \mathrm{~A}$ in RV-A1, VP1/2A could not be cleaved by
$2 \mathrm{~A}^{\text {pro }}$. The C-terminal three residues of VP1 are necessary for this cleavage in CV-B1 (Muto et al., 2006). It has shown that $2 \mathrm{~A}^{\text {pro }}$ can cleave foreign proteins inserted between VP1 and $2 \mathrm{~A}$ in an attenuated but infectious and replicative CV-B3 genome (Zeng et al., 2013). PV 2A $\mathrm{A}^{\text {pro }}$ can cleave the polyprotein accurately after a red fluorescent protein (DsRed) is inserted after residue 144 in 2A (Teterina et al., 2010). This indicates that the cis-cleavage function can be used to develop expression vectors.

In addition to its cis-cleavage function, $2 \mathrm{~A}^{\text {pro }}$ can also influence virus replication. $\mathrm{PV} 2 \mathrm{~A}^{\text {pro }}$ is required for viral polysome formation and stability (Kempf and Barton, 2008). PV 2A $\mathrm{A}^{\text {pro }}$, together with the $5^{\prime}$ cloverleaf-poly $(\mathrm{C})$ binding protein complex and $3^{\prime} \operatorname{poly}(\mathrm{A})$ tail, is required for the optimal translation of PV RNA (Ogram et al., 2010). It is sufficient to induce eIF2-independent IRES-driven translation alone (Redondo et al., 2011). However, it is not a prerequisite for the replication of the PV genome (Igarashi et al., 2010). The $2 \mathrm{~A}^{\text {pro }}$ of EV-A71 and CV-B3 exhibited strong transcriptional activities in yeast cells. The C-terminal acid domain is essential for the transcriptional activity of $2 \mathrm{~A}^{\text {pro }}$ (Yang et al., 2010). 


A $\quad$ EV $-A 71$
CV $-A 16$
CV-B3
PV1
RV-A
Consensus


EV-A71
CV-A16
CV-B3
PV1
RV-A
COnsensus

B DHAV-1_2A3

$\mathrm{EPV}-1-2 \mathrm{~A} 2$
consensus

avisivirus_2A1

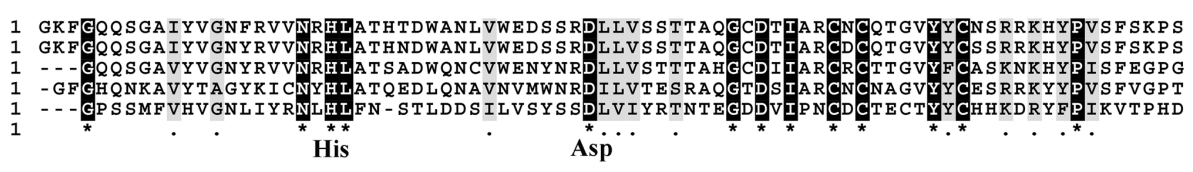

His

Asp

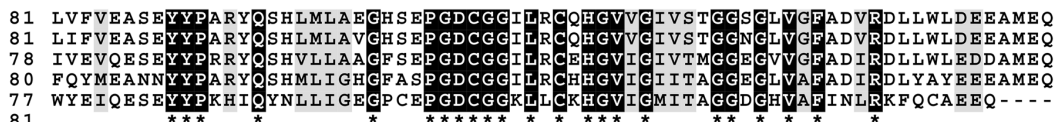

Cys
$\mathrm{EE} Q$
galivivirus_2A

AIV $2 \mathrm{~A}$

$\mathrm{BKV}^{-2 \mathrm{~A}}$

$\mathrm{PKV}^{-} 2 \mathrm{~A}$

$\mathrm{HPe} \overline{\mathrm{V}}-1-2 \mathrm{~A}$
$\mathrm{LV} 2 \mathrm{~A} 2$

Passerivirus 2A

DHAV - $1 \quad 2$ A 3

gallivirus $2 \mathrm{~A}$

AIV $2 \mathrm{~A}$

$\mathrm{BKV}-2 \mathrm{~A}$
$\mathrm{PKV}$

HPe $\bar{V}-1$ - $2 \mathrm{~A}$

LV 2 A 2

Passerivirus_2A

$\mathrm{EPV}-1$ - $2 \mathrm{~A} 2$

conseñsus

C TEV

SAFV

GFTV

consensus

$\begin{array}{ll}\text { TEV } & 7 \\ \text { VHEV } & 7 \\ \text { SAFV } & 7 \\ \text { GFTV } & 7 \\ \text { EMCV } & 8 \\ \text { CONSEnsus } & 8\end{array}$

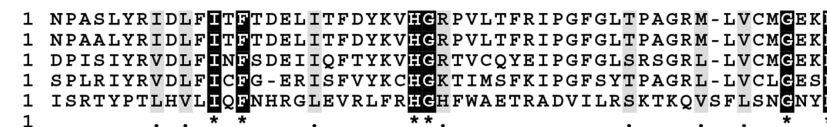

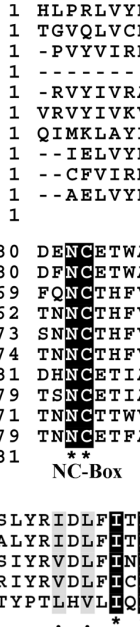
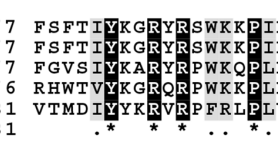

IHDELVDRGYTTFREFFKAVRGYHADYYK

LHDELYDYGFSTFTDFFKAVRDYHASYYKQ

HEEVGE - GFETFNE FFKFIRS IHSSYYHMR

..

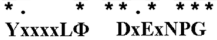

D Avisivirus_2A1

Aquamavirus $2 \mathrm{~A}$

PTV - 1

Pasivirus_AI

Mischiviru

LV $2 \mathrm{~A} 1$

FMDV - 2 A 2

FHMPV $2 \mathrm{~A} 1$

FHMPV $\overline{1}$

ERAV

Cosavirus_A

CPV - 1_2 A 2

$\mathrm{CPV}-1_{-}^{-2 \mathrm{~A}}$

BRBV

Hunnivirus

$B G P V-1 \quad 2 A 2$

BGPV - 1-2A

consensus

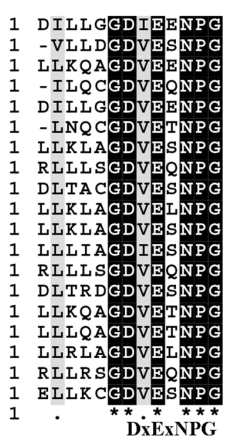

FIGURE 3 | Sequence alignment of each type of 2A protein. The alignment was completed using MEGA6 and ClustalX2. (A) Alignment of chymotrypsin-like 2As.

(B) Alignment of Parechovirus-like 2As. (C) Alignment of 2As from the genus Cardiovirus. (D) Alignment of Aphthovirus-like 2 As. The * means that the amino acids at this site are identical.

TABLE 1 | The five types of 2A proteins.

Types of $2 \mathrm{~A}$

Chymotrypsin-like 2A

Parechovirus-like 2A

Unique 2A in HAV

Aphthovirus-like 2A

Unique 2A sequence in cardiovirus

\section{Functional motif}

Cys-His-Asp

H-NC box

No relevant functional motif was identified

DxExNPGP

NPGP, elF4E binding site, NLS

\section{Common functions performed}

Affect host translation, apoptosis, interferon pathway, nuclear transport, induced cardiomyopathy

Viral replication and cell proliferation

Involved in virus assembly

Ribosomal skipping mechanism

Ribosomal skipping mechanism,Affect host translation and nuclear localization 


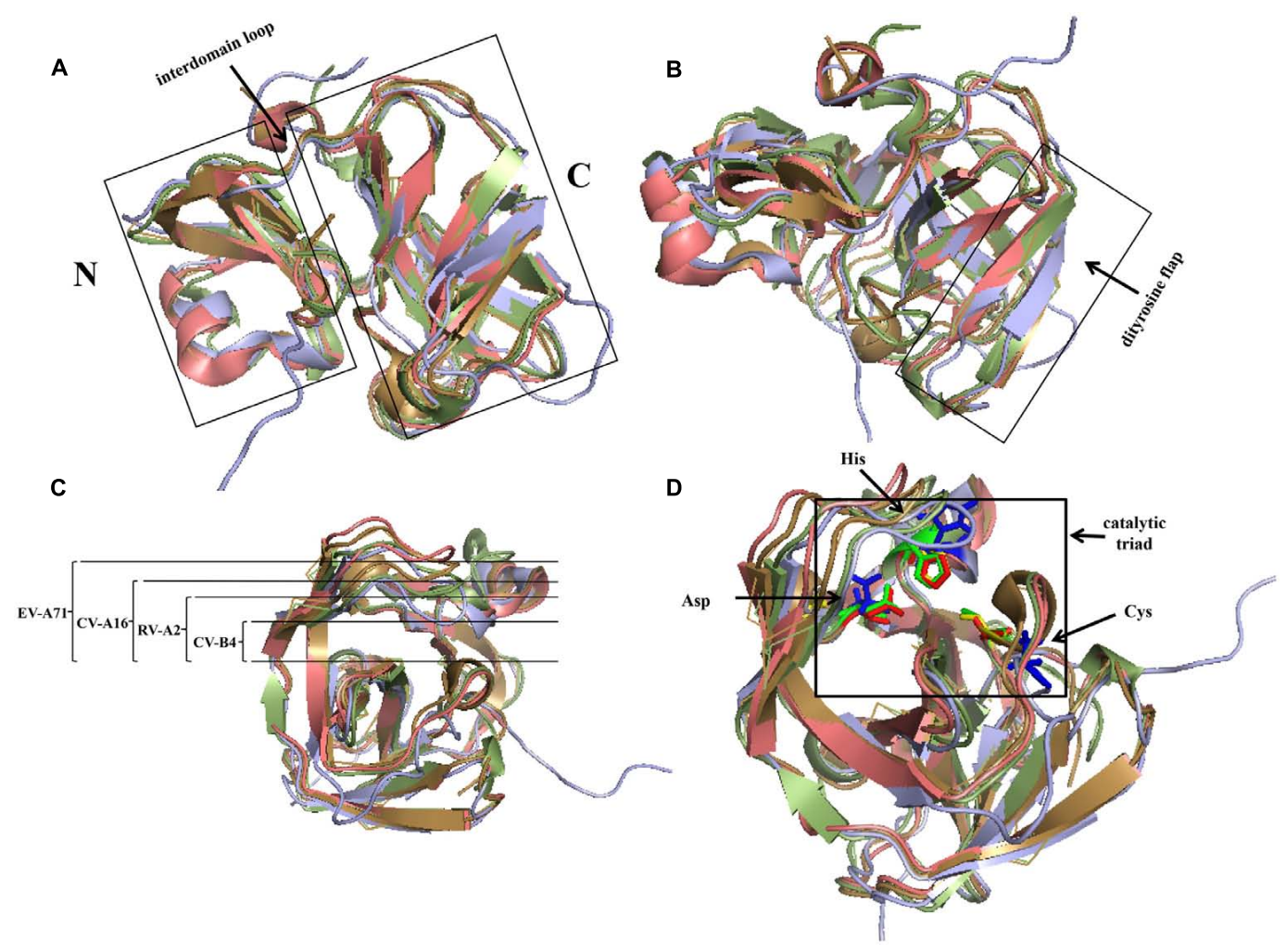

FIGURE 4 | Comparison of structures of four common chymotrypsin-like 2A proteins using PyMOL. The 2A structures of RV-A2, CV-B4, CV-A16, and EV-A71 are represented in pale green, lilac, beige, and salmon, respectively. (A) The left and right domains are the $\mathrm{N}$ - and $\mathrm{C}$-terminus, respectively, which are connected via an interdomain loop. (B) C-terminal dityrosine flap. (C) Open cleft across the surface of the protein. The width of EV-A71 is the largest, followed by that of CV-A16, and that of RV-A2 is the narrowest. (D) Active sites of 2A pro. The active sites of the 2As of RV-A2, CV-B4, CV-A16, and EV-A71 are represented in green, blue, yellow, and red, respectively. (PDB code: RV-A2, 2HRV; CV-B4, 1Z8R; CV-A16, 4MG3; EV-A71, 4FVD).

TABLE 2 | Active sites of the catalytic triad in several chymotrypsin-like 2A proteins.

\begin{tabular}{|c|c|c|c|c|c|c|c|}
\hline Active sites of catalytic triad & HRV-C2 & HRV2 & EV71 & PV & CVB4 & CVB3 & CVA16 \\
\hline Cys & 105 & 106 & 110 & 109 & 110 & 110 & 110 \\
\hline His & 34 & 18 & 21 & 20 & 21 & 18 & 21 \\
\hline Asp & 18 & 35 & 39 & 38 & 39 & 35 & 39 \\
\hline
\end{tabular}

\section{Function of $2 A^{\text {pro }}$ with Respect to the Host}

During virus infection, $2 \mathrm{~A}^{\text {pro }}$ plays a critical role in shutting down host protein synthesis (Lloyd, 2006). It cleaves eIF4G to halt cap-dependent host translation (Krausslich et al., 1987; Lloyd et al., 1988; Chau et al., 2007). The eIF4G protein is a subunit of eIF4F that facilitates mRNA unwinding and ribosome binding to mRNA. The eIF4F complex contains three subunits: eIF4E, eIF4G, and eIF4A. It has been shown that RV $2 \mathrm{~A}^{\text {pro }}$ can cleave the eIF4G-eIF4E complex more efficiently than eIF4G alone (Haghighat et al., 1996). Moreover, 2A ${ }^{\text {pro }}$ from RV-A2 and CV-B4 can form a stable complex with eIF4GII/eIF4E, but not with eIF4GII alone (Aumayr et al., 2015). These findings suggest that the eIF4F complex may be a preferred substrate for this cleavage. RV 2A proteins cleave eIF4GI at different cleavage sites (Sousa et al., 2006). Cleaving only eIF4G does not completely shut down host translation. However, when $2 \mathrm{~A}^{\text {pro }}$ also cleaves PABP, translational activity is completely prevented (Joachims et al., 1999) (Figure 5A). By cleaving eIF4G, PV $2 \mathrm{~A}^{\text {pro }}$ can inhibit the synthesis of HIV-1 proteins, the translation of which is mainly cap-dependent during the early translational phase (Amorim et al., 2014). EV $2 \mathrm{~A}^{\text {pro }}$-mediated eIF4G cleavage can also inhibit the IV IRES activity of duck hepatitis A virus (DHAV) (Pan et al., 2012). In contrast, this event can rescue the translation of Sindbis virus replicons when the genuine leader sequence of the mRNA is replaced by the picornaviral IRES (Sanz et al., 2010). CV-B3 2A pro can also promote the replication of EMCV by inhibiting cellular cap-dependent translation (Song et al., 2015).

$2 \mathrm{~A}^{\text {pro }}$ plays an important role in apoptosis. PV $2 \mathrm{~A}^{\text {pro }}$ can inhibit apoptosis during later-stage infection by inducing aberrant cleavage of procaspase-9 (Burgon et al., 2009). In contrast, CV-B3 $2 \mathrm{~A}^{\text {pro }}$ can induce apoptosis via multiple 
converging pathways. Firstly, CV-B3 $2 \mathrm{~A}^{\text {pro }}$ can induce caspase-8mediated activation of caspase- 3 and cleavage of PARP; secondly, it can activate the intrinsic mitochondria-mediated apoptosis pathway to induce the release of cytochrome $c$ and activate caspase-9 via cleavage of $\mathrm{BH} 3$ interacting-domain death agonist (BID) (Chau et al., 2007) (Figure 5C).

Many picornaviruses target the IFN pathways to gain a replication advantage. The melanoma differentiation-associated gene 5 (MDA5)/mitochondrial antiviral-signaling protein (MAVS) pathway is responsible for recognizing EV infections (such as EV-A71 infection) of host cells and can induce IFN-I expression. Enteroviruses such as EV-A71 can employ 2Apro to cleave MDA5 and MAVS, thus blocking the production of IFN-I (Feng et al., 2014). The cleavage sites in MAVS are Gly209, Gly251, and Gly265 (Wang et al., 2013). EV-A71 2A pro $^{\text {can }}$ cleave the IFN receptor (IFN alpha and beta receptor subunit 1, IFNAR1) to block IFN-induced Janus kinase (Jak)/signal transducer and activator of transcription (STAT) signaling (Wang C.Y. et al., 2015). It can also cause the attenuation of IFN- $\gamma$ signaling by reducing the serine phosphorylation of STAT1 (Wang L.C. et al., 2015) (Figure 5B). Viruses with chymotrypsin-like $2 \mathrm{~A}^{\text {pro }}$ are able to replicate in IFN- $\alpha$-pretreated cells while EMCV is completely inhibited; the addition of $2 \mathrm{~A}^{\text {pro }}$ to the EMCV genome can prevent the inhibition. This suggests that $2 \mathrm{~A}^{\text {pro }}$ plays an inhibitory role in the downstream event of IFN signaling (Morrison and Racaniello, 2009).

The traffic of biological molecules between the nucleus and cytoplasm occurs via the NPC, which is embedded in the nuclear membrane and is composed of multiple Nups. 2A $\mathrm{A}^{\text {pro }}$ can influence the nucleo-cytoplasm by cleaving Nups, thus disrupting

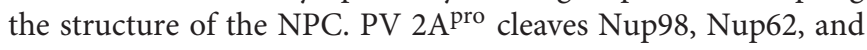
Nup153 to interfere with the trafficking of mRNAs, rRNAs, and $\mathrm{U}$ small nuclear RNAs (U snRNAs) from the nucleus to the cytoplasm, but without affecting the transport of tRNA (Castello et al., 2009) (Figure 5D). RV-A2 2A pro cleaves Nup62 at six sites (Park et al., 2010) and Nup98 at two key sites, Gly374 and Gly552 (Park et al., 2015). Different RV 2A proteins cleave Nups at different sites (Watters and Palmenberg, 2011). In addition, $2 \mathrm{~A}^{\text {pro }}$ can affect the location of several specific biomolecules. PV and RV-A $162 \mathrm{~A}^{\text {pro }}$ can induce efficient cytoplasmic relocation of the cellular splicing factor SRp20, which is an important IRES trans-acting factor for PV IRES-mediated translation (Fitzgerald et al., 2013). PV $2 \mathrm{~A}^{\text {pro }}$ also induces the selective nucleo-cytoplasm translocation of HuR and TIA1/TIAR in order to modulate splicing of the human Fas exon 6 (Alvarez et al., 2013). In addition, $\mathrm{PV} 2 \mathrm{~A}^{\text {pro }}$ can cause the viral proteins $3 \mathrm{CD}$ and $3 C^{\prime}$ to move to the nucleus from the cytoplasm (Tian et al., 2011).

CV-B3 $2 \mathrm{~A}^{\text {pro }}$ can cleave the cytoskeletal protein dystrophin, thus causing severe dilated cardiomyopathy in the host (Xiong et al., 2007; Lim et al., 2013). Moreover, the release of the C-terminal fragment of dystrophin can cause more severe cardiomyopathy (Barnabei et al., 2015). CV-B3 2A pro can also cleave serum response factor (Wong et al., 2012) and interact with human cardiomyocyte proteins (Zhao et al., 2016) to induce dilated cardiomyopathy, but the detailed mechanisms are unclear.
In addition to the common functions above, different $2 \mathrm{~A}$ proteins also have several other functions to resist the host response. EV-A71 2A $\mathrm{A}^{\text {pro }}$ can cleave the spliced X-box-binding protein 1 that is required for plasma cell differentiation (Jheng et al., 2012). It can also cleave the NACHT, LRR, and PYD domains-containing protein 3 (NLRP3) inflammasome at the G493-L494 junction to resist the host immune response during later-stage infection (Wang $\mathrm{H}$. et al., 2015). CV-B3 2A ${ }^{\text {pro }}$ can downregulate the expression of cyclic AMP responsive element binding protein, which functions as a transcription factor (Chau et al., 2007), and cleave the Grb2-associated binder 1, which is an important docking protein responsible for intracellular signaling system assembly and signal transduction (Deng et al., 2015). CV-B3 and EV-A71 2As can trigger stress granule formation (Wu et al., 2014). RV 2A $\mathrm{A}^{\text {pro }}$ can activate monocytederived dendritic cells in vitro and induce strong Th1 and Th2 immune responses from CD4 $\mathrm{T}$ cells during upper and lower respiratory tract infections in patients with severe chronic obstructive pulmonary disease (Singh et al., 2010).

\section{Antiviral Inhibitors of $2 A^{\text {pro }}$}

In summary, $2 \mathrm{~A}^{\text {pro }}$ plays an essential role in resisting host defenses during virus infection. It evades the host immune responses in multiple ways. Blocking the interaction of the virus with the host can effectively improve host resistance, thus increasing resistance against virus infection. Due to its unique protein structure and its essential role in viral replication, $2 \mathrm{~A}^{\text {pro }}$ is regarded as an excellent target for antiviral intervention. A great number of inhibitors have successfully been developed as substrate analogs that bind to the protein's active sites (Wang, 2001). The short peptide LVLQTM and a modified form, z-LVLQTM-fmk, can both specifically inhibit 2A pro (Falah et al., 2012a,b). The novel compound CW-33 can inhibit the enzymatic activity of $2 \mathrm{~A}^{\text {pro }}$, thus recovering the expression of IFNAR1 in EV-A71-infected cells (Wang C.Y. et al., 2015). A synthesized 16-mer peptide can also specifically block the activity of CV-B3 $2 \mathrm{~A}^{\text {pro }}$ (Maghsoudi et al., 2010). In addition, several drugs can inhibit the activity of $2 \mathrm{~A}^{\text {pro }}$ via other mechanisms. The indirubin derivative E804 inhibits the $2 \mathrm{~A}^{\text {pro }}$-dependent cleavage of $3 \mathrm{CD}$, thus interfering with CV-B3 polyprotein processing (Ford Siltz et al., 2014). zVAD.fmk is a general inhibitor and its derivative zVAM.fmk can specially inhibit RV 2A pro (Deszcz et al., 2006). Chlorogenic acid, which is the major active ingredient in many traditional Chinese herbs, exhibits antiviral properties against EV-A71 by inhibiting transcription and translation of $2 \mathrm{~A}^{\text {pro }}$ (Li et al., 2013).

\section{CONSERVED MOTIFS AND FUNCTIONS OF PARECHOVIRUS-LIKE 2A}

The Parechovirus-like 2A sequences are not proteases. This type of $2 \mathrm{~A}$ has a conserved $\mathrm{H}-\mathrm{NC}$ box, and some versions have a putative transmembrane domain (Hughes and Stanway, 2000). These 2A proteins are related to the cellular $\mathrm{H}$-rev107 family, the members of which are involved in the control of cell proliferation (Tsai et al., 2009; Wei et al., 2015). In addition, the H-NC box is 


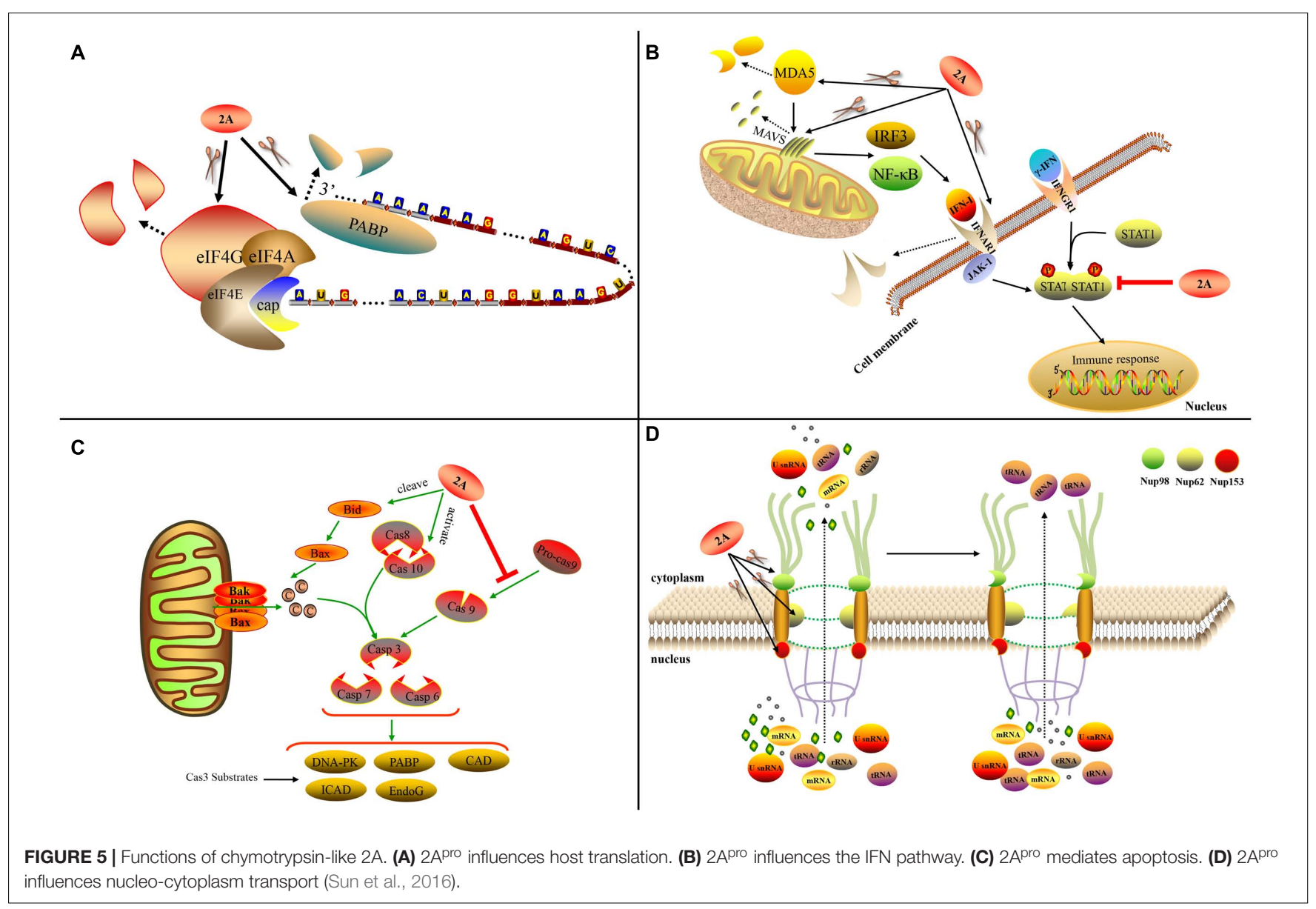

involved in virus replication. During $\mathrm{HPeV}$ infection, the bulk of the $2 \mathrm{~A}$ proteins localize to the perinuclear area and some colocalize with the viral RNA (Samuilova et al., 2004; Krogerus et al., 2007). Parechovirus-like 2A possesses RNA-binding activity and preferentially binds to the viral $3^{\prime}$ untranslated region (UTR) (Samuilova et al., 2004). Parechovirus-like 2A can interact with all of the non-structural proteins except for $\mathrm{L}$ and $3 \mathrm{AB}$. The strongest interaction occurs between 2A and 3CD (Ishikawa et al., 2010). In AIV, the efficient cleavage of $\mathrm{VP} 1 / 2 \mathrm{~A}$ requires interaction between 3CD and 2A (Sasaki et al., 2012). The H-NC box in the $2 \mathrm{~A}$ protein is essential for AIV replication. Mutation of the NC motif abolishes virus replication by affecting both negative- and positive-strand synthesis (Sasaki and Taniguchi, 2008). These findings indicate that this type of $2 \mathrm{~A}$ may play important roles in replication complexes by interaction with viral proteins and RNA during viral RNA replication. Targeting this 2A protein may affect the formation of the replication complex, thus combatting virus proliferation.

\section{UNIQUE 2A PROTEIN IN HEPATITIS A VIRUS (HAV)}

No functional motifs have been found in the 2A gene of HAV. This type of $2 \mathrm{~A}$ protein is considered a structural component and it is involved in morphogenesis. The HAV 2A protein, together with the VP1 protein as a precursor, is responsible for the virulence of HAV (Emerson et al., 2002). The deletion of $10-15$ aa from the central portion of the $2 \mathrm{~A}$ protein does not affect the protein's processing and the mutant virus is able to replicate relatively well (Harmon et al., 1995). The 2A protein does not function in cis as a $2 \mathrm{AB}$ precursor (Beard et al., 2001). The cleavage at the HAV $2 \mathrm{~A} / 2 \mathrm{~B}$ junction is carried out by $3 \mathrm{C}^{\text {pro }}$ at Gln836/Ala837 (Jia et al., 1993; Martin et al., 1995). The released $\mathrm{P} 1-2 \mathrm{~A}$ acts as a functional precursor. $2 \mathrm{~A}$, as a part of $\mathrm{P} 1-2 \mathrm{~A}$, is a primary signal for the assembly of pentameric viral structures

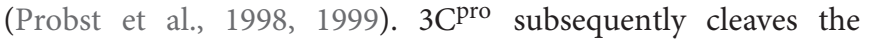
precursor to generate VP0, VP3, and VP1-2A. These products, which associate as pentamers, constitute the icosahedral viral capsid. Subsequently, cleavage occurs at the VP1/2A junction to release the mature $2 \mathrm{~A}$ protein (Cohen et al., 2002). This cleavage is carried out by cellular proteinases such as Factor Xa, trypsin, and cathepsin L (Figure 6) and it requires $\mathrm{Arg}^{278}$ to be present at the VP1/2A junction (Rachow et al., 2003; Morace et al., 2008). Targeting this $2 \mathrm{~A}$ protein may interfere the formation of the icosahedral viral capsid. In addition, the $2 \mathrm{~A}$ protein can strongly inhibit human growth hormone (the translation of which is entirely cap-dependent) via an unknown mechanism (Maltese et al., 2000). VP1-2A can also reduce the viability of Huh-7 cells (Kanda et al., 2006). 


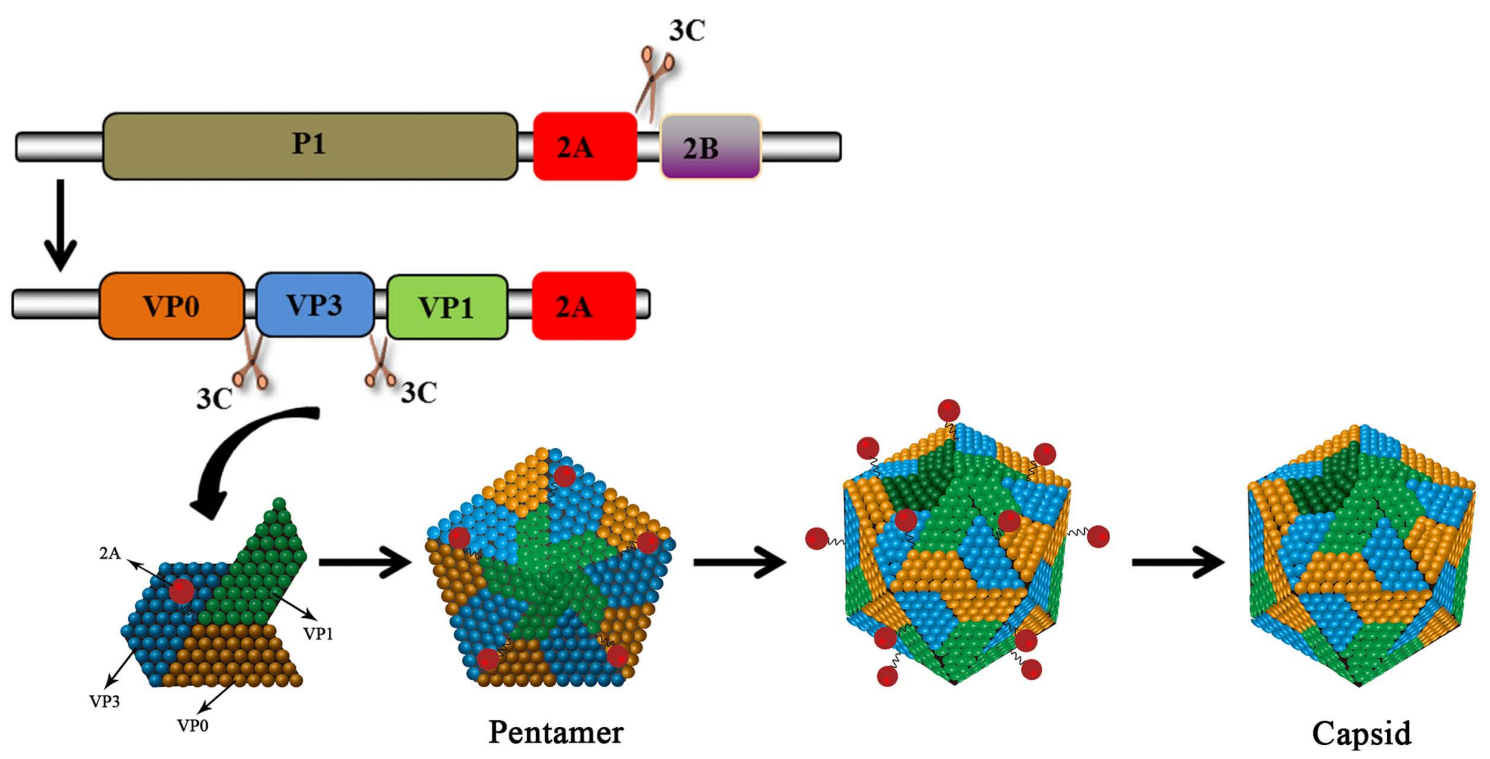

FIGURE 6 | HAV 2A is involved in viral capsid assembly. The HAV protein precursor is cleaved by 3C pro to produce VP0, VP3, and VP1-2A. The products assemble into pentamers that then assemble into icosahedral viral capsids. 2A (as part of VP1-2A) is involved in virus assembly. The VP1/2A junction is then cleaved by cellular proteases to release $2 \mathrm{~A}$.

\section{MECHANISM AND FUNCTION MEDIATED BY APHTHOVIRUS-LIKE 2A PEPTIDE}

\section{Ribosomal Skipping Mechanism for "Self-Cleavage" in the Viral Translation Process}

The FMDV 2A protein (F2A) in Aphthovirus is a short peptide containing only $18 \mathrm{aa}$. $3 \mathrm{C}^{\text {pro }}$ can only successfully process the $\mathrm{P} 1$ polyprotein into the structural protein $\mathrm{VP} 1$ when $2 \mathrm{~A}$ is present (Guo et al., 2013). However, the 2A protein does not affect the assembly of empty capsid particles nor the viability of the virus (Gullberg et al., 2013). Along with the first residue of $2 \mathrm{~B}$, the $2 \mathrm{~A}$ sequence comprises a conserved C-terminal DxExNPGP motif. This 2A-like sequence is found in many mammalian viruses and a wide range of insect viruses (Luke et al., 2008). The DxExNPGP motif induces a co-translational "cleavage" event that releases $\mathrm{P} 1-2 \mathrm{~A}$ from the P2 polyprotein. This permits the translation of $\mathrm{P} 2$ after $\mathrm{P} 1-2 \mathrm{~A}$ is released from the ribosome (Donnelly et al., 2001b; Grubman and Baxt, 2004). The cleavage requires neither eIFs nor eRFs. The cleavage is carried out by the ribosome and eukaryotic elongation factors 1 and 2 (eEF-1 and -2) (Machida et al., 2014). It is assumed that F2A promotes hydrolysis of the peptidyl (2A)$\mathrm{tRNA}^{\mathrm{Gly}}$ ester linkage, thus releasing the polypeptide from the translational complex. This process causes the ribosome to "skip" from one codon to the next without forming a peptide bond (Figure 7). The ribosomal skipping activity can be affected by the C-terminal sequence of the protein upstream. The 3040aa upstream sequence highly influences the skipping activity (Minskaia and Ryan, 2013). The upstream capsid VP1 sequences increase the skipping activity of F2A. N-terminal truncation of $2 \mathrm{~A}$ sequences decreases the skipping activity and 13 residues are required for minimum activity. The "uncleaved" polyprotein cannot be cleaved later (Ryan and Drew, 1994). When using artificial polyprotein systems, there was a molar excess of the $\mathrm{N}$-terminal product of this translational event compared with the C-terminal product; however, this phenomenon does not occur in the natural P12A2B2C context (Donnelly et al., 2001b). This is consistent with the idea that the artificial systems do not represent the optimal functioning environment for this translational event; not all ribosomes continue to synthesize the protein downstream (Donnelly et al., 2001a). The mutation of D within the DxExNPGP motif abrogates the F2A cleavage activity (Donnelly et al., 1997). The synonymous mutation of $G$ has no effect on the skipping efficiency (Gao et al., 2014). In contrast, mutation of the first $G$ to $D$ in the GxExNPGP motif of the $2 \mathrm{~A}$ protein of infectious flacherie virus abolishes the skipping activity (Donnelly et al., 2001a). F2A does not exhibit the skipping activity in prokaryotic translation systems (Donnelly et al., 1997).

Simultaneous expression of multiple genes is frequently required in genetic engineering (de Felipe et al., 1999). The Aphthovirus-like 2A sequences are increasingly preferred for this purpose due to their small size and high cleavage efficiency (de Felipe, 2004). Compared with IRES, 2A mediates a more efficient expression of the downstream protein (Chan et al., 2011), with levels up to $\sim 4$ times greater than those mediated by IRES (Chinnasamy et al., 2006). It has been shown that the incorporation of viral $2 \mathrm{~A}$ sequences into polycistronic vectors does not cause unwanted immune responses against TD cells (Arber et al., 2013). For biomedical applications, the 30 residues of F2A have been shown to be the most optimal residues 


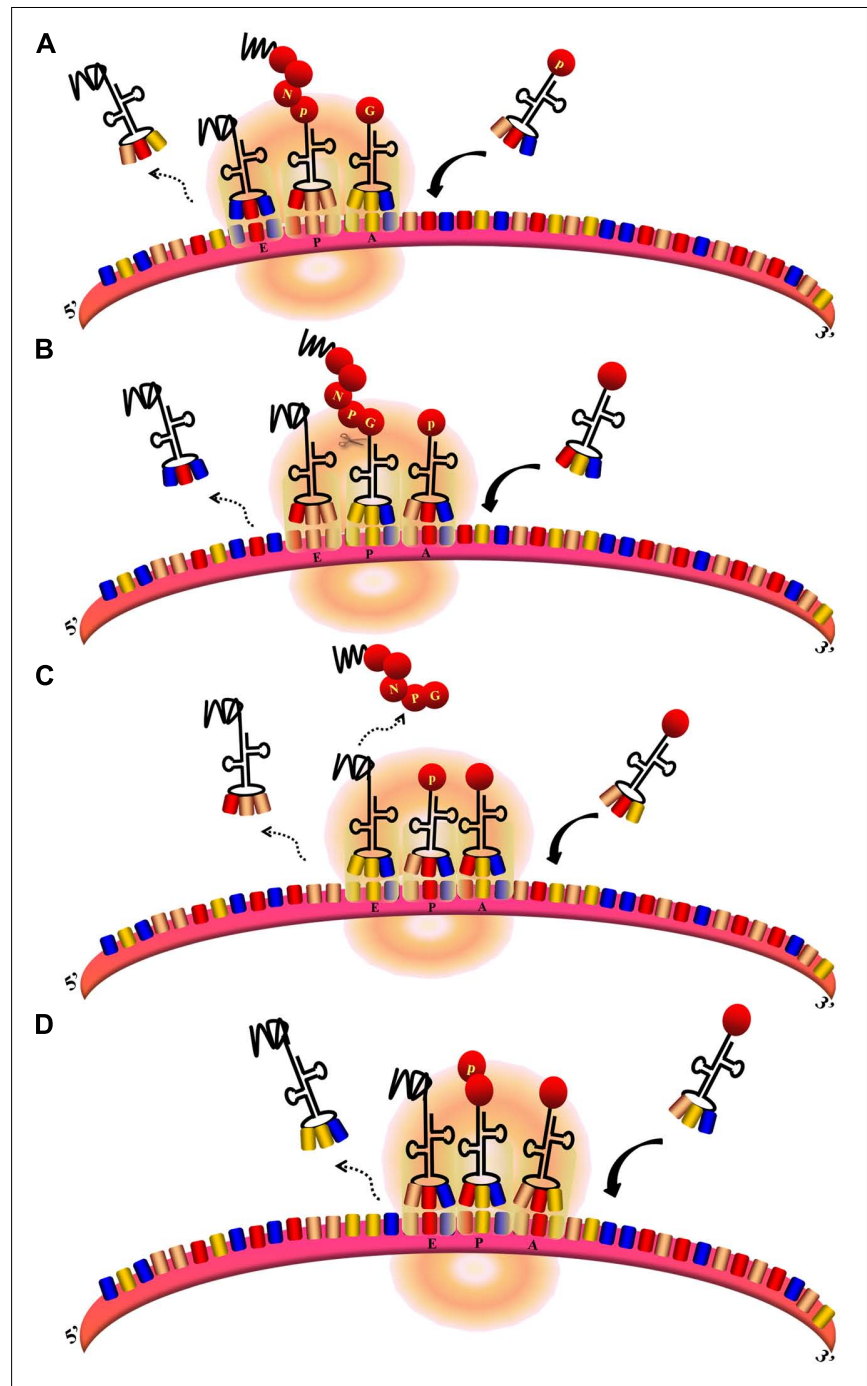

FIGURE 7 | Ribosomal skipping mechanism mediated by Aphthovirus-like 2A sequences (Donnelly et al., 2001b). (A,B) During the peptide chain extension process, the ribosome moves toward the $3^{\prime} U T R$ of the mRNA. The deaminoacyl-tRNA at the $E$ site is released, the peptidyl-tRNA at the $P$ site is transferred to the E site, and the aminoacyl-tRNA at the A site is transferred to the $P$ site to allow the next aminoacyl-tRNA to enter the A site. At the same time, the peptide chain at the $E$ site is transferred to the $P$ site and forms a peptide bond with the amino acid at this site. (B-D) When the translation of $2 \mathrm{~A}$ is finished, aminoacyl-tRNA ${ }^{(P r o)}$ enters the $\mathrm{A}$ site. The peptide chain is hydrolyzed from the peptidyl-tRNA at the P site. The depeptidyl-tRNA is then transferred to the $E$ site and the aminoacyl-tRNA ${ }^{(P r o)}$ is transferred to the $P$ site. The new aminoacyl-tRNA enters the A site as normal. Subsequent translation proceeds normally.

in terms of both length and cleavage efficiency (Minskaia et al., 2013). The cleavage efficiencies of $2 \mathrm{~A}$ sequences from FMDV, ERAV, TAV, and PTV-1 show that the $2 \mathrm{~A}$ protein of PTV-1 has the highest cleavage efficiency (Kim et al., 2011). Aphthovirus-like 2A has been used to express transgenes in multiple circumstances. It can be used in oncolytic adenoviruses (Funston et al., 2008), lentiviral vectors (Chinnasamy et al., 2006), retroviral vectors (de Felipe et al., 1999), recombinant adeno-associated viruses (Furler et al., 2001), and influenza virus vectors (Tan et al., 2016) to express multicistronic genes.

\section{Application of Aphthovirus-Like 2A}

The Aphthovirus-like 2A has been successfully used in multiple expression systems, including those in plants and parasites, demonstrating its extensive application range. It has been used to efficiently co-express the two functional subunits of bovine interleukin-12 (IL-12) (Chaplin et al., 1999), subunit p19 of IL23, p40 of IL-12 (Yen and Scheerlinck, 2013), and the heavy and light chains of full-length coagulation factor VIII (He et al., 2011). The co-expression of porcine IFN- $\alpha$ and IFN- $\gamma$ using F2A can enhance their antiviral effects against FMDV (Kim et al., 2014). F2A significantly improved the lentiviral Cre recombinase delivery system designed to provide a specific Cre activity level (Liu et al., 2012).

This $2 \mathrm{~A}$ can also ensure stable expression of multiple proteins introduced into plant cells (Halpin et al., 1999). It does not affect the localization of the co-expressed proteins, so it is a useful tool for studying plant intracellular trafficking (Buren et al., 2012). The co-expression of lignocellulose hydrolysis enzymes linked by the F2A protein provides a novel low-cost enzyme system for hydrolyzing lignocellulosic material (Lee et al., 2012). In microalgae, F2A can be used to resolve a major obstacle of poor expression of heterologous genes in the nuclear genome (Rasala et al., 2012). In addition, F2A has also been used to co-express glycine betaine synthesis genes in the yeast Pichia pastoris (Wang et al., 2007). Moreover, the F2Amediated heterogeneous glycosylphosphatidylinositol-anchored proteins co-displaying yeast system is an effective method for improving the efficiency of enzyme-displaying yeast biocatalysts (Sun et al., 2012). In addition, F2A has been used to co-express five Taenia solium (pork tapeworm) immunogens in plant cells (Monreal-Escalante et al., 2015). The 2A protein of PTV-1 has also been successfully used to co-express multi-proteins in parasites (Tang et al., 2016).

\section{CONSERVATIVE MOTIF OF FUNCTION OF THE UNIQUE 2A SEQUENCE IN CARDIOVIRUS}

The members of the genus Cardiovirus possess a unique 2A protein. This protein has a DxExNPGP motif, an YxxxxL $\Phi$ motif, and a NLS. The ribosomal skipping motif functions effectively (Donnelly et al., 2001a). The YxxxxL $\Phi$ motif fits the eIF4E binding site used by eIF4G to interact with eIF4E (Groppo et al., 2011). The L proteins of EMCV, TMEV, and SAFV use the NLS in $2 \mathrm{~A}$ to enhance their trafficking to the nucleus; in turn, 2A prevents L phosphorylation (Petty et al., 2014). Binding to host eIF4E is a potential mechanism by which the $2 \mathrm{~A}$ protein shuts down host translation (Groppo et al., 2011). In addition, EMCV 2A can shut down host translation by tightly associating with free $40 \mathrm{~S}$ ribosome subunits (Groppo and Palmenberg, 2007). The 2A protein is also required for inhibition of apoptosis (Carocci et al., 
2011), probably because apoptosis can affect the survival of the virus. In addition, during EMCV infection, recombinant adenovirus containing the precursor protein $\mathrm{P} 1 / 2 \mathrm{~A}$ and $3 \mathrm{C}^{\text {pro }}$ can elicit more efficacious protection than the one containing P1 alone (Chen et al., 2008). This indicates the necessity of processing $\mathrm{P} 1 / 2 \mathrm{~A}$ to generate a sufficient neutralizing antibody response.

\section{VIRUSES CONTAINING MULTIPLE 2A PROTEINS}

Most of the members of Picornaviridae have only one 2A protein, but during evolution, some viruses miraculously acquired multiple 2As. These multiple $2 \mathrm{~A}$ proteins in single viruses can be the same or different, and can thus perform corresponding or divergent functions. This phenomenon is unique to picornaviruses. The members of Limnipivirus contains two Aphthovirus-like 2A proteins (Barbknecht et al., 2014; Lange et al., 2014). The LV also contains two 2A proteins, but one is Aphthovirus-like 2A and the other is Parechovirus-like 2A (Johansson et al., 2002). It has been reported that DHAV1 has three in-tandem 2A genes (Tseng and Tsai, 2007b; Jin et al., 2008). They encode the 2A1, 2A2, and 2A3 proteins, which are Aphthovirus-like 2A, AIG1-like 2A with a GTPase motif, and Parechovirus-like 2A, respectively (Tseng and Tsai, 2007a; Tseng et al., 2007). In contrast, other researchers suggest that DHAV-1 contains only two 2A proteins, an Aphthoviruslike 2A1 and a Parechovirus-like 2A2 with an AIG1 domain at the N-terminus (Kim et al., 2006; Ding and Zhang, 2007). Viruses in the genus Megrivirus possess three potential 2A peptides, one of which, 2A3, contains an H-NC box (Boros et al., 2014b; Liao et al., 2014). A turkey avisivirus 1 (TuASV1) possesses three $2 \mathrm{~A}$ proteins (potentially similar to DHAV-1), but the $2 \mathrm{~A} 1$ protein contains two DxExNPGP motifs (Boros et al., 2013). The newly discovered picornavirus Aalivirus contains six 2A proteins, including four Aphthovirus-like 2As (2A1-2A4), an AIG1-like 2A5, and a Parechovirus-like 2A6 (Wang et al., 2014) (Figure 1B). The diversity of 2A proteins suggests that multiple recombination events occurred during their evolution. It appears that the $2 \mathrm{~A}$ proteins have provided a very strong advantage to picornaviruses during evolution in that they provide multiple powerful functions for use during viral infection. The viruses that have acquired multiple 2A proteins have mostly been obtained from avian hosts (Boros et al., 2014c), suggesting that picornaviruses infecting avian hosts may have more complex mechanisms than other picornaviruses.

\section{CONCLUSION}

Among the five types of $2 \mathrm{~A}$ proteins, chymotrypsin-like $2 \mathrm{~A}^{\text {pro }}$ represents a relatively large category. For $2 \mathrm{~A}^{\text {pro }}$, substrate recognition does not involve the certain amino acid sequences but rather undetermined restricted spatial factors (Neubauer et al., 2013), so its conformation is important for maintaining its function. $2 \mathrm{~A}^{\text {pro }}$ prevents host immune responses via multiple mechanisms and utilizes host factors to enhance viral replication. The development of inhibitors of $2 \mathrm{~A}^{\text {pro }}$ requires a rational strategy based on its structure and function. We can improve upon the existing inhibitors that target the structure of $2 \mathrm{~A}^{\text {pro }}$ to improve resistance to viral infection.

The Aphthovirus-like 2A sequence that mediates the ribosomal skipping mechanism represents another large category of $2 \mathrm{~A}$ proteins. These short $2 \mathrm{~A}$ peptides can mediate a unique translation mechanism alone. It is still unclear what factors are involved in the translation process; although a tentative functional mechanism has been suggested, it needs to be explored further. These short 2A peptides have been widely used in genetic engineering to co-express multiple genes. Compared to other co-expression methods, this technique offers powerful advantages. Nevertheless, it still has several flaws that have yet to be overcome. Solving these problems will help to improve the practical application of the short $2 \mathrm{~A}$ peptides.

In addition to the two major classes of $2 \mathrm{~A}$ proteins, all other 2A proteins play important roles in virus replication and resisting host immune responses via distinctive mechanisms. These complicated functions and corresponding structures still require more in-depth exploration.

The evolution of the $2 \mathrm{~A}$ protein has been extremely fast, and diverse $2 \mathrm{~A}$ proteins have evolved. The highly non-conserved nature of the $2 \mathrm{~A}$ protein causes great difficulty for researchers. Its unusually rapid evolutionary rate suggests that it is involved in additional host interactions (Hughes, 2004). This indicates that $2 \mathrm{~A}$ plays a pivotal role in virus infection. It has been shown that the AIG-I-like 2A2 protein of DHAV-1 can induce apoptosis (Cao et al., 2016). As none of the five types of $2 \mathrm{~A}$ protein reviewed in this paper possess this capacity, the AIGI-like 2A2 protein of DHAV-1 may have to be classified as a distinct type of $2 \mathrm{~A}$ protein. Moreover, there are some $2 \mathrm{~A}$ proteins that have yet to be recognized (Boros et al., 2014a; Liao et al., 2014). The phenomenon of multiple types of $2 \mathrm{~A}$ proteins existing in one virus family is extremely rare. In addition, although the phenomenon of multiple types of $2 \mathrm{~A}$ proteins existing in one virus family is extremely rare, discovering why some viruses have acquired multiple 2 As remains an important and challenging issue to be explored. All of the above problems cause great difficulties for researchers regarding using a single specific $2 \mathrm{~A}$ protein as a model. The widespread prevalence of picornaviruses has caused a large number of cases of disease and large losses in production. Preventing these viral infections is an urgent problem to be solved. This review has provided evidence indicating the usefulness of targeting $2 \mathrm{~A}$ when designing specific inhibitors and other strategies to resist picornaviruses.

\section{AUTHOR CONTRIBUTIONS}

XY wrote the manuscript and produced the figures. AC, MW, and $\mathrm{RJ}$ revised the manuscript. KS, KP, and QY provided the ideas 
for the figures. YW, DZ, and SC revised the figures. ML, X-XZ, and $\mathrm{XC}$ helped with proofreading. All of the authors edited the manuscript.

\section{FUNDING}

This work was supported by grants from the National Natural Science Foundation of China (31472223), National Science and Technology Support Program (No. 2015BAD12B05), China

\section{REFERENCES}

Adams, M. J., Lefkowitz, E. J., King, A. M., Harrach, B., Harrison, R. L., Knowles, N. J., et al. (2016). Ratification vote on taxonomic proposals to the International Committee on Taxonomy of Viruses (2016). Arch. Virol. 161, 2921-2949. doi: 10.1007/s00705-016-2977-6

Alvarez, E., Castello, A., Carrasco, L., and Izquierdo, J. M. (2013). Poliovirus $2 \mathrm{~A}$ protease triggers a selective nucleo-cytoplasmic redistribution of splicing factors to regulate alternative pre-mRNA splicing. PLoS ONE 8:e73723. doi: 10.1371/journal.pone.0073723

Amorim, R., Costa, S. M., Cavaleiro, N. P., da Silva, E. E., and da Costa, L. J. (2014). HIV-1 transcripts use IRES-initiation under conditions where Cap-dependent translation is restricted by poliovirus 2A protease. PLOS ONE 9:e88619. doi: 10.1371/journal.pone.0088619

Arber, C., Abhyankar, H., Heslop, H. E., Brenner, M. K., Liu, H., Dotti, G., et al. (2013). The immunogenicity of virus-derived $2 \mathrm{~A}$ sequences in immunocompetent individuals. Gene Ther. 20, 958-962. doi: 10.1038/gt. 2013.25

Aumayr, M., Fedosyuk, S., Ruzicska, K., Sousa-Blin, C., Kontaxis, G., and Skern, T. (2015). NMR analysis of the interaction of picornaviral proteinases $\mathrm{Lb}$ and $2 \mathrm{~A}$ with their substrate eukaryotic initiation factor 4GII. Protein Sci. 24, 1979-1996. doi: $10.1002 /$ pro. 2807 .

Barbknecht, M., Sepsenwol, S., Leis, E., Tuttle-Lau, M., Gaikowski, M., Knowles, N. J., et al. (2014). Characterization of a new picornavirus isolated from the freshwater fish Lepomis macrochirus. J. Gen. Virol. 95(Pt 3), 601-613. doi: 10. 1099/vir.0.061960-0

Barnabei, M. S., Sjaastad, F. V., Townsend, D., Bedada, F. B., and Metzger, J. M. (2015). Severe dystrophic cardiomyopathy caused by the enteroviral protease 2A-mediated C-terminal dystrophin cleavage fragment. Sci. Transl. Med. 7:294ra106. doi: 10.1126/scitranslmed. aaa 4804

Baxter, N. J., Roetzer, A., Liebig, H. D., Sedelnikova, S. E., Hounslow, A. M., Skern, T., et al. (2006). Structure and dynamics of coxsackievirus B4 2A proteinase, an enyzme involved in the etiology of heart disease. J. Virol. 80, 1451-1462. doi: 10.1128/jvi.80.3.1451-1462.2006

Beard, M. R., Cohen, L., Lemon, S. M., and Martin, A. (2001). Characterization of recombinant hepatitis A virus genomes containing exogenous sequences at the 2A/2B junction. J. Virol. 75, 1414-1426. doi: 10.1128/jvi.75.3.1414-1426. 2001

Boros, A., Nemes, C., Pankovics, P., Kapusinszky, B., Delwart, E., and Reuter, G. (2013). Genetic characterization of a novel picornavirus in turkeys (Meleagris gallopavo) distinct from turkey galliviruses and megriviruses and distantly related to the members of the genus Avihepatovirus. J. Gen. Virol. 94, 1496-1509. doi: 10.1099/vir.0.051797-0

Boros, A., Pankovics, P., Adonyi, A., Phan, T. G., Delwart, E., and Reuter, G. (2014a). Genome characterization of a novel chicken picornavirus distantly related to the members of genus Avihepatovirus with a single 2A protein and a megrivirus-like 3' UTR. Infect. Genet. Evol. 28, 333-338. doi: 10.1016/j.meegid. 2014.10.025

Boros, A., Pankovics, P., Knowles, N. J., Nemes, C., Delwart, E., and Reuter, G. (2014b). Comparative complete genome analysis of chicken and Turkey megriviruses (family Picornaviridae): long $3^{\prime}$ untranslated regions with a potential second open reading frame and evidence for possible recombination. J. Virol. 88, 6434-6443. doi: 10.1128/jvi.03807-13
Agricultural Research System (CARS-43-8), and Special Fund for Key Laboratory of Animal Disease and Human Health of Sichuan Province (2016JPT0004).

\section{ACKNOWLEDGMENT}

We apologize to the authors of articles reporting relevant research that were not cited in this manuscript due to limited space.

Boros, A., Pankovics, P., and Reuter, G. (2014c). Avian picornaviruses: molecular evolution, genome diversity and unusual genome features of a rapidly expanding group of viruses in birds. Infect. Genet. Evol. 28, 151-166. doi: 10.1016/j.meegid.2014.09.027

Buren, S., Ortega-Villasante, C., Otvos, K., Samuelsson, G., Bako, L., and Villarejo, A. (2012). Use of the foot-and-mouth disease virus 2A peptide coexpression system to study intracellular protein trafficking in Arabidopsis. PLoS ONE 7:e51973. doi: 10.1371/journal.pone.0051973

Burgon, T. B., Jenkins, J. A., Deitz, S. B., Spagnolo, J. F., and Kirkegaard, K. (2009). Bypass suppression of small-plaque phenotypes by a mutation in poliovirus 2A that enhances apoptosis. J. Virol. 83, 10129-10139. doi: 10.1128/jvi.00642-09

Cai, Q., Yameen, M., Liu, W., Gao, Z., Li, Y., Peng, X., et al. (2013). Conformational plasticity of the 2A proteinase from enterovirus 71. J. Virol. 87, 7348-7356. doi: 10.1128/jvi.03541-12

Cao, J., Ou, X., Zhu, D., Ma, G., Cheng, A., Wang, M., et al. (2016). The 2A2 protein of Duck hepatitis A virus type 1 induces apoptosis in primary cell culture. Virus Genes 52, 780-788. doi: 10.1007/s11262-016-1364-4

Carocci, M., Cordonnier, N., Huet, H., Romey, A., Relmy, A., Gorna, K., et al. (2011). Encephalomyocarditis virus 2A protein is required for viral pathogenesis and inhibition of apoptosis. J. Virol. 85, 10741-10754. doi: 10.1128/jvi.00394-11

Castello, A., Izquierdo, J. M., Welnowska, E., and Carrasco, L. (2009). RNA nuclear export is blocked by poliovirus $2 \mathrm{~A}$ protease and is concomitant with nucleoporin cleavage. J. Cell Sci. 122, 3799-3809. doi: 10.1242/jcs.055988

Chan, H. Y., Sivakamasundari, V., Xing, X., Kraus, P., Yap, S. P., Ng, P., et al. (2011). Comparison of IRES and F2A-based locus-specific multicistronic expression in stable mouse lines. PLOS ONE 6:e28885. doi: 10.1371/journal.pone. 0028885

Chaplin, P. J., Camon, E. B., Villarreal-Ramos, B., Flint, M., Ryan, M. D., and Collins, R. A. (1999). Production of interleukin-12 as a self-processing 2A polypeptide. J. Interferon Cytokine Res. 19, 235-241. doi: 10.1089/ 107999099314162

Chau, D. H., Yuan, J., Zhang, H., Cheung, P., Lim, T., Liu, Z., et al. (2007). Coxsackievirus $\mathrm{B} 3$ proteases $2 \mathrm{~A}$ and $3 \mathrm{C}$ induce apoptotic cell death through mitochondrial injury and cleavage of eIF4GI but not DAP5/p97/NAT1. Apoptosis 12, 513-524. doi: 10.1007/s10495-006-0013-0

Chen, Z., Guo, X., Ge, X., Jia, H., and Yang, H. (2008). Protective immune response in mice vaccinated with a recombinant adenovirus containing capsid precursor polypeptide $\mathrm{P} 1$, nonstructural protein $2 \mathrm{~A}$ and $3 \mathrm{C}$ protease genes (P12A3C) of encephalomyocarditis virus. Vaccine 26, 573-580. doi: 10.1016/j.vaccine.2007. 11.027

Chinnasamy, D., Milsom, M. D., Shaffer, J., Neuenfeldt, J., Shaaban, A. F., Margison, G. P., et al. (2006). Multicistronic lentiviral vectors containing the FMDV 2A cleavage factor demonstrate robust expression of encoded genes at limiting MOI. Virol. J. 3:14. doi: 10.1186/1743-422x-3-14

Cohen, L., Benichou, D., and Martin, A. (2002). Analysis of deletion mutants indicates that the 2A polypeptide of hepatitis A virus participates in virion morphogenesis. J. Virol. 76, 7495-7505. doi: 10.1128/JVI.76.15.7495-7505.2002

de Felipe, P. (2004). Skipping the co-expression problem: the new 2A "CHYSEL" technology. Genet. Vaccines Ther. 2:13. doi: 10.1186/1479-0556-2-13

de Felipe, P., Martin, V., Cortes, M. L., Ryan, M., and Izquierdo, M. (1999). Use of the $2 \mathrm{~A}$ sequence from foot-and-mouth disease virus in the generation of retroviral vectors for gene therapy. Gene Ther. 6, 198-208. doi: 10.1038/sj.gt. 3300811 
Deng, H., Fung, G., Shi, J., Xu, S., Wang, C., Yin, M., et al. (2015). Enhanced enteroviral infectivity via viral protease-mediated cleavage of Grb2-associated binder 1. FASEB J. 29, 4523-4531. doi: 10.1096/fj.15-274829

Deszcz, L., Cencic, R., Sousa, C., Kuechler, E., and Skern, T. (2006). An antiviral peptide inhibitor that is active against picornavirus $2 \mathrm{~A}$ proteinases but not cellular caspases. J. Virol. 80, 9619-9627. doi: 10.1128/jvi.00612-06

Ding, C., and Zhang, D. (2007). Molecular analysis of duck hepatitis virus type 1. Virology 361, 9-17. doi: 10.1016/j.virol.2007.01.007

Donnelly, M. L., Gani, D., Flint, M., Monaghan, S., and Ryan, M. D. (1997). The cleavage activities of aphthovirus and cardiovirus 2A proteins. J. Gen. Virol. 78, 13-21. doi: 10.1099/0022-1317-78-1-13

Donnelly, M. L., Hughes, L. E., Luke, G., Mendoza, H., ten Dam, E., Gani, D., et al. (2001a). The 'cleavage' activities of foot-and-mouth disease virus $2 \mathrm{~A}$ sitedirected mutants and naturally occurring '2A-like' sequences. J. Gen. Virol. 82, 1027-1041. doi: 10.1099/0022-1317-82-5-1027

Donnelly, M. L., Luke, G., Mehrotra, A., Li, X., Hughes, L. E., Gani, D., et al. (2001b). Analysis of the aphthovirus 2A/2B polyprotein 'cleavage' mechanism indicates not a proteolytic reaction, but a novel translational effect: a putative ribosomal 'skip'. J. Gen. Virol. 82, 1013-1025. doi: 10.1099/0022-1317-82-51013

Emerson, S. U., Huang, Y. K., Nguyen, H., Brockington, A., Govindarajan, S., St Claire, M., et al. (2002). Identification of VP1/2A and $2 \mathrm{C}$ as virulence genes of hepatitis A virus and demonstration of genetic instability of 2C. J. Virol. 76, 8551-8559. doi: 10.1128/JVI.76.17.8551-8559.2002

Falah, N., Montserret, R., Lelogeais, V., Schuffenecker, I., Lina, B., Cortay, J. C., et al. (2012a). Blocking human enterovirus 71 replication by targeting viral $2 \mathrm{~A}$ protease. J. Antimicrob. Chemother. 67, 2865-2869. doi: 10.1093/jac/dks304

Falah, N., Violot, S., Decimo, D., Berri, F., Foucault-Grunenwald, M. L., Ohlmann, T., et al. (2012b). Ex vivo and in vivo inhibition of human rhinovirus replication by a new pseudosubstrate of viral 2A protease. J. Virol. 86, 691-704. doi: 10.1128/jvi.05263-11

Feng, Q., Langereis, M. A., Lork, M., Nguyen, M., Hato, S. V., Lanke, K., et al. (2014). Enterovirus 2Apro targets MDA5 and MAVS in infected cells. J. Virol. 88, 3369-3378. doi: 10.1128/jvi.02712-13

Fitzgerald, K. D., Chase, A. J., Cathcart, A. L., Tran, G. P., and Semler, B. L. (2013). Viral proteinase requirements for the nucleocytoplasmic relocalization of cellular splicing factor SRp20 during picornavirus infections. J. Virol. 87, 2390-2400. doi: 10.1128/jvi.02396-12

Ford Siltz, L. A., Viktorova, E. G., Zhang, B., Kouiavskaia, D., Dragunsky, E., Chumakov, K., et al. (2014). New small-molecule inhibitors effectively blocking picornavirus replication. J. Virol. 88, 11091-11107. doi: 10.1128/jvi.01877-14

Funston, G. M., Kallioinen, S. E., de Felipe, P., Ryan, M. D., and Iggo, R. D. (2008). Expression of heterologous genes in oncolytic adenoviruses using picornaviral 2A sequences that trigger ribosome skipping. J. Gen. Virol. 89, 389-396. doi: 10.1099/vir.0.83444-0

Furler, S., Paterna, J. C., Weibel, M., and Bueler, H. (2001). Recombinant AAV vectors containing the foot and mouth disease virus $2 \mathrm{~A}$ sequence confer efficient bicistronic gene expression in cultured cells and rat substantia nigra neurons. Gene Ther. 8, 864-873. doi: 10.1038/sj.gt.3301469

Gao, Z. L., Zhou, J. H., Zhang, J., Ding, Y. Z., and Liu, Y. S. (2014). The silent point mutations at the cleavage site of $2 \mathrm{~A} / 2 \mathrm{~B}$ have no effect on the self-cleavage activity of 2A of foot-and-mouth disease virus. Infect. Genet. Evol. 28, 101-106. doi: 10.1016/j.meegid.2014.08.006

Glaser, W., Triendl, A., and Skern, T. (2003). The processing of eIF4GI by human rhinovirus type 2 Apro: relationship to self-cleavage and role of zinc. J. Virol. 77, 5021-5025. doi: 10.1128/JVI.77.8.5021-5025.2003

Groppo, R., Brown, B. A., and Palmenberg, A. C. (2011). Mutational analysis of the EMCV 2A protein identifies a nuclear localization signal and an eIF4E binding site. Virology 410, 257-267. doi: 10.1016/j.virol.2010.11.002

Groppo, R., and Palmenberg, A. C. (2007). Cardiovirus 2A protein associates with $40 \mathrm{~S}$ but not $80 \mathrm{~S}$ ribosome subunits during infection. J. Virol. 81, 13067-13074. doi: 10.1128/jvi.00185-07

Grubman, M. J., and Baxt, B. (2004). Foot-and-mouth disease. Clin. Microbiol. Rev. 17, 465-493. doi: 10.1128/CMR.17.2.465-493.2004

Gullberg, M., Polacek, C., Botner, A., and Belsham, G. J. (2013). Processing of the $\mathrm{VP} 1 / 2 \mathrm{~A}$ junction is not necessary for production of foot-and-mouth disease virus empty capsids and infectious viruses: characterization of "self-tagged" particles. J. Virol. 87, 11591-11603. doi: 10.1128/jvi.01863-13
Guo, C., Zhang, C., Zheng, H., and Huang, Y. (2013). Recombinant adenovirus expression of FMDV P1-2A and 3C protein and its immune response in mice. Res. Vet. Sci. 95, 736-741. doi: 10.1016/j.rvsc.2013.05.001

Haghighat, A., Svitkin, Y., Novoa, I., Kuechler, E., Skern, T., and Sonenberg, N. (1996). The eIF4G-eIF4E complex is the target for direct cleavage by the rhinovirus 2A proteinase. J. Virol. 70, 8444-8450.

Halpin, C., Cooke, S. E., Barakate, A., El Amrani, A., and Ryan, M. D. (1999). Selfprocessing 2A-polyproteins-a system for co-ordinate expression of multiple proteins in transgenic plants. Plant J. 17, 453-459. doi: 10.1046/j.1365-313X. 1999.00394.x

Harmon, S. A., Emerson, S. U., Huang, Y. K., Summers, D. F., and Ehrenfeld, E. (1995). Hepatitis A viruses with deletions in the $2 \mathrm{~A}$ gene are infectious in cultured cells and marmosets. J. Virol. 69, 5576-5581.

He, B., Pan, Y., Chen, L., Xu, Y., Chen, N., Gu, L., et al. (2011). Stable expression of native Coagulation factor VIII using the $2 \mathrm{~A}$ self-processing sequence and furin cleavage site. Thromb. Res. 128, e148-e153. doi: 10.1016/j.thromres.2011. 07.015

Hellen, C. U., Facke, M., Krausslich, H. G., Lee, C. K., and Wimmer, E. (1991). Characterization of poliovirus $2 \mathrm{~A}$ proteinase by mutational analysis: residues required for autocatalytic activity are essential for induction of cleavage of eukaryotic initiation factor 4F polypeptide p220. J. Virol. 65, 4226-4231.

Hughes, A. L. (2004). Phylogeny of the Picornaviridae and differential evolutionary divergence of picornavirus proteins. Infect. Genet. Evol. 4, 143-152. doi: 10. 1016/j.meegid.2004.03.001

Hughes, P. J., and Stanway, G. (2000). The 2A proteins of three diverse picornaviruses are related to each other and to the H-rev107 family of proteins involved in the control of cell proliferation. J. Gen. Virol. 81, 201-207. doi: 10.1099/0022-1317-81-1-201

Igarashi, H., Yoshino, Y., Miyazawa, M., Horie, H., Ohka, S., and Nomoto, A. (2010). 2A protease is not a prerequisite for poliovirus replication. J. Virol. 84, 5947-5957. doi: 10.1128/jvi.02575-09

Ishikawa, K., Sasaki, J., and Taniguchi, K. (2010). Overall linkage map of the nonstructural proteins of Aichi virus. Virus Res. 147, 77-84. doi: 10.1016/j. virusres.2009.10.009

Jheng, J. R., Lin, C. Y., Horng, J. T., and Lau, K. S. (2012). Inhibition of enterovirus 71 entry by transcription factor XBP1. Biochem. Biophys. Res. Commun. 420, 882-887. doi: 10.1016/j.bbrc.2012.03.094

Jia, X. Y., Summers, D. F., and Ehrenfeld, E. (1993). Primary cleavage of the HAV capsid protein precursor in the middle of the proposed $2 \mathrm{~A}$ coding region. Virology 193, 515-519. doi: 10.1006/viro.1993.1157

Jin, X., Zhang, W., Zhang, W., Gu, C., Cheng, G., and Hu, X. (2008). Identification and molecular analysis of the highly pathogenic duck hepatitis virus type 1 in Hubei province of China. Res. Vet. Sci. 85, 595-598. doi: 10.1016/j.rvsc.2008. 01.001

Joachims, M., Van Breugel, P. C., and Lloyd, R. E. (1999). Cleavage of poly(A)binding protein by enterovirus proteases concurrent with inhibition of translation in vitro. J. Virol. 73, 718-727.

Johansson, S., Niklasson, B., Maizel, J., Gorbalenya, A. E., and Lindberg, A. M. (2002). Molecular analysis of three Ljungan virus isolates reveals a new, closeto-root lineage of the Picornaviridae with a cluster of two unrelated $2 \mathrm{~A}$ proteins. J. Virol. 76, 8920-8930. doi: 10.1128/JVI.76.17.8920-8930.2002

Kanda, T., Yokosuka, O., Imazeki, F., Fujiwara, K., and Saisho, H. (2006). Hepatitis A protein VP1-2A reduced cell viability in Huh-7 cells with hepatitis $\mathrm{C}$ virus subgenomic RNA replication. J. Gastroenterol. Hepatol. 21, 625-626. doi: 10. 1111/j.1440-1746.2006.04253.x

Kempf, B. J., and Barton, D. J. (2008). Poliovirus $2 \mathrm{~A}^{\text {Pro }}$ increases viral mRNA and polysome stability coordinately in time with cleavage of eIF4G. J. Virol. 82, 5847-5859. doi: 10.1128/jvi.01514-07

Kim, J. H., Lee, S. R., Li, L. H., Park, H. J., Park, J. H., Lee, K. Y., et al. (2011). High cleavage efficiency of a $2 \mathrm{~A}$ peptide derived from porcine teschovirus-1 in human cell lines, zebrafish and mice. PLoS ONE 6:e18556. doi: 10.1371/journal. pone. 0018556

Kim, M. C., Kwon, Y. K., Joh, S. J., Lindberg, A. M., Kwon, J. H., Kim, J. H., et al. (2006). Molecular analysis of duck hepatitis virus type 1 reveals a novel lineage close to the genus Parechovirus in the family Picornaviridae. J. Gen. Virol. 87, 3307-3316. doi: 10.1099/vir.0.81804-0

Kim, S. M., Kim, S. K., Park, J. H., Lee, K. N., Ko, Y. J., Lee, H. S., et al. (2014). A recombinant adenovirus bicistronically expressing porcine interferon-alpha 
and interferon-gamma enhances antiviral effects against foot-and-mouth disease virus. Antiviral Res. 104, 52-58. doi: 10.1016/j.antiviral.2014.01.014

Krausslich, H. G., Nicklin, M. J., Toyoda, H., Etchison, D., and Wimmer, E. (1987). Poliovirus proteinase $2 \mathrm{~A}$ induces cleavage of eucaryotic initiation factor $4 \mathrm{~F}$ polypeptide p220. J. Virol. 61, 2711-2718.

Krogerus, C., Samuilova, O., Poyry, T., Jokitalo, E., and Hyypia, T. (2007). Intracellular localization and effects of individually expressed human parechovirus 1 non-structural proteins. J. Gen. Virol. 88, 831-841. doi: 10.1099/ vir.0.82201-0

Lange, J., Groth, M., Fichtner, D., Granzow, H., Keller, B., Walther, M., et al. (2014). Virus isolate from carp: genetic characterization reveals a novel picornavirus with two aphthovirus 2A-like sequences. J. Gen. Virol. 95, 80-90. doi: 10.1099/ vir.0.058172-0

Lee, D. S., Lee, K. H., Jung, S., Jo, E. J., Han, K. H., and Bae, H. J. (2012). Synergistic effects of 2A-mediated polyproteins on the production of lignocellulose degradation enzymes in tobacco plants. J. Exp. Bot. 63, 4797-4810. doi: 10.1093/ jxb/ers159

Lee, W., Watters, K. E., Troupis, A. T., Reinen, N. M., Suchy, F. P., Moyer, K. L., et al. (2014). Solution structure of the $2 \mathrm{~A}$ protease from a common cold agent, human rhinovirus C2, strain W12. PLOS ONE 9:e97198. doi: 10.1371/journal. pone.0097198

Li, X., Liu, Y., Hou, X., Peng, H., Zhang, L., Jiang, Q., et al. (2013). Chlorogenic acid inhibits the replication and viability of enterovirus 71 in vitro. PLoS ONE 8:e76007. doi: 10.1371/journal.pone.0076007

Liao, Q., Zheng, L., Yuan, Y., Shi, J., and Zhang, D. (2014). Genomic characterization of a novel picornavirus in Pekin ducks. Vet. Microbiol. 172, 78-91. doi: 10.1016/j.vetmic.2014.05.002

Lim, B. K., Peter, A. K., Xiong, D., Narezkina, A., Yung, A., Dalton, N. D., et al. (2013). Inhibition of Coxsackievirus-associated dystrophin cleavage prevents cardiomyopathy. J. Clin. Invest. 123, 5146-5151. doi: 10.1172/jci66271

Liu, K., Wang, H., Long, Y., Ye, J., and Yuan, L. (2012). Coordinate lentiviral expression of Cre recombinase and RFP/EGFP mediated by FMDV 2A and analysis of Cre activity. J. Cell. Biochem. 113, 2909-2919. doi: 10.1002/jcb.24168

Lloyd, R. E. (2006). Translational control by viral proteinases. Virus Res. 119, 76-88. doi: 10.1016/j.virusres.2005.10.016

Lloyd, R. E., Grubman, M. J., and Ehrenfeld, E. (1988). Relationship of p220 cleavage during picornavirus infection to $2 \mathrm{~A}$ proteinase sequencing. J. Virol. 62 , 4216-4223.

Luke, G. A., de Felipe, P., Lukashev, A., Kallioinen, S. E., Bruno, E. A., and Ryan, M. D. (2008). Occurrence, function and evolutionary origins of '2A-like' sequences in virus genomes. J. Gen. Virol. 89, 1036-1042. doi: 10.1099/vir.0. 83428-0

Machida, K., Mikami, S., Masutani, M., Mishima, K., Kobayashi, T., and Imataka, H. (2014). A translation system reconstituted with human factors proves that processing of encephalomyocarditis virus proteins $2 \mathrm{~A}$ and $2 \mathrm{~B}$ occurs in the elongation phase of translation without eukaryotic release factors. J. Biol. Chem. 289, 31960-31971. doi: 10.1074/jbc.M114.593343

Maghsoudi, A. H., Khodagholi, F., Hadi-Alijanvand, H., Esfandiarei, M., Sabbaghian, M., Zakeri, Z., et al. (2011). Homology modeling, docking, molecular dynamics simulation, and structural analyses of coxsakievirus B3 2A protease: an enzyme involved in the pathogenesis of inflammatory myocarditis. Int. J. Biol. Macromol. 49, 487-492. doi: 10.1016/j.ijbiomac.2011.05.023

Maghsoudi, N., Khodagholi, F., Sadjadi, M., Zeinodini, M., and Sabbaghian, M. (2008). Purification and partial characterization of coxsackievirus B3 2A protease expressed in Escherichia coli. Int. J. Biol. Macromol. 43, 238-244. doi: 10.1016/j.ijbiomac.2008.05.008

Maghsoudi, N., Tafreshi, N., Khodagholi, F., Zakeri, Z., Esfandiarei, M., HadiAlijanvand, H., et al. (2010). Targeting enteroviral 2A protease by a $16-\mathrm{mer}$ synthetic peptide: inhibition of 2Apro-induced apoptosis in a stable Tet-on HeLa cell line. Virology 399, 39-45. doi: 10.1016/j.virol.2009.12.017

Maltese, E., Bucci, M., Macchia, S., Latorre, P., Pagnotti, P., Pierangeli, A., et al. (2000). Inhibition of cap-dependent gene expression induced by protein $2 \mathrm{~A}$ of hepatitis A virus. J. Gen. Virol. 81, 1373-1381. doi: 10.1099/0022-1317-81-51373

Martin, A., Escriou, N., Chao, S. F., Girard, M., Lemon, S. M., and Wychowski, C. (1995). Identification and site-directed mutagenesis of the primary (2A/2B) cleavage site of the hepatitis A virus polyprotein: functional impact on the infectivity of HAV RNA transcripts. Virology 213, 213-222. doi: 10.1006/viro. 1995.1561

Minskaia, E., Nicholson, J., and Ryan, M. D. (2013). Optimisation of the foot-andmouth disease virus $2 \mathrm{~A}$ co-expression system for biomedical applications. BMC Biotechnol. 13:67. doi: 10.1186/1472-6750-13-67

Minskaia, E., and Ryan, M. D. (2013). Protein coexpression using FMDV 2A: effect of "linker" residues. Biomed. Res. Int. 2013:291730. doi: 10.1155/2013/291730

Monreal-Escalante, E., Banuelos-Hernandez, B., Hernandez, M., Fragoso, G., Garate, T., Sciutto, E., et al. (2015). Expression of multiple taenia solium immunogens in plant cells through a ribosomal skip mechanism. Mol. Biotechnol. 57, 635-643. doi: 10.1007/s12033-015-9853-6

Morace, G., Kusov, Y., Dzagurov, G., Beneduce, F., and Gauss-Muller, V. (2008). The unique role of domain $2 \mathrm{~A}$ of the hepatitis A virus precursor polypeptide P1-2A in viral morphogenesis. BMB Rep. 41, 678-683. doi: 10.5483/BMBRep. 2008.41.9.678

Morrison, J. M., and Racaniello, V. R. (2009). Proteinase 2Apro is essential for enterovirus replication in type I interferon-treated cells. J. Virol. 83, 4412-4422. doi: 10.1128/jvi.02177-08

Mu, Z., Wang, B., Zhang, X., Gao, X., Qin, B., Zhao, Z., et al. (2013). Crystal structure of $2 \mathrm{~A}$ proteinase from hand, foot and mouth disease virus. J. Mol. Biol. 425, 4530-4543. doi: 10.1016/j.jmb.2013.08.016

Muto, S., Miyoshi, H., Nishikawa, H., and Nakashima, H. (2006). Novel recognition sequence of coxsackievirus 2A proteinase. Biochem. Biophys. Res. Commun. 348, 1436-1442. doi: 10.1016/j.bbrc.2006.08.012

Neubauer, D., Aumayr, M., Gosler, I., and Skern, T. (2013). Specificity of human rhinovirus 2Apro is determined by combined spatial properties of four cleavage site residues. J. Gen. Virol. 94, 1535-1546. doi: 10.1099/vir.0. 051201-0

Ogram, S. A., Spear, A., Sharma, N., and Flanegan, J. B. (2010). The 5'CL-PCBP RNP complex, $3^{\prime}$ poly(A) tail and 2 Apro are required for optimal translation of poliovirus RNA. Virology 397, 14-22. doi: 10.1016/j.virol.2009.11.006

Pan, M., Yang, X., Zhou, L., Ge, X., Guo, X., Liu, J., et al. (2012). Duck Hepatitis A virus possesses a distinct type IV internal ribosome entry site element of picornavirus. J. Virol. 86, 1129-1144. doi: 10.1128/jvi.00306-11

Park, N., Schweers, N. J., and Gustin, K. E. (2015). Selective removal of FG repeat domains from the nuclear pore complex by enterovirus 2Apro. J. Virol. 89, 11069-11079. doi: 10.1128/jvi.00956-15

Park, N., Skern, T., and Gustin, K. E. (2010). Specific cleavage of the nuclear pore complex protein Nup62 by a viral protease. J. Biol. Chem. 285, 28796-28805. doi: 10.1074/jbc.M110.143404

Petty, R. V., Basta, H. A., Bacot-Davis, V. R., Brown, B. A., and Palmenberg, A. C. (2014). Binding interactions between the encephalomyocarditis virus leader and protein 2A. J. Virol. 88, 13503-13509. doi: 10.1128/jvi.02148-14

Probst, C., Jecht, M., and Gauss-Muller, V. (1998). Processing of proteinase precursors and their effect on hepatitis A virus particle formation. J. Virol. 72, 8013-8020.

Probst, C., Jecht, M., and Gauss-Muller, V. (1999). Intrinsic signals for the assembly of hepatitis A virus particles. Role of structural proteins VP4 and 2A. J. Biol. Chem. 274, 4527-4531. doi: 10.1074/jbc.274.8.4527

Rachow, A., Gauss-Muller, V., and Probst, C. (2003). Homogeneous hepatitis A virus particles. Proteolytic release of the assembly signal 2A from procapsids by factor Xa. J. Biol. Chem. 278, 29744-29751. doi: 10.1074/jbc.M30045 4200

Rasala, B. A., Lee, P. A., Shen, Z., Briggs, S. P., Mendez, M., and Mayfield, S. P. (2012). Robust expression and secretion of Xylanase1 in Chlamydomonas reinhardtii by fusion to a selection gene and processing with the FMDV 2A peptide. PLoS ONE 7:e43349. doi: 10.1371/journal.pone.0043349

Redondo, N., Sanz, M. A., Welnowska, E., and Carrasco, L. (2011). Translation without eIF2 promoted by poliovirus 2A protease. PLOS ONE 6:e25699. doi: 10.1371/journal.pone.0025699

Ryan, M. D., and Drew, J. (1994). Foot-and-mouth disease virus 2A oligopeptide mediated cleavage of an artificial polyprotein. EMBO J. 13, 928-933.

Samuilova, O., Krogerus, C., Poyry, T., and Hyypia, T. (2004). Specific interaction between human parechovirus nonstructural $2 \mathrm{~A}$ protein and viral RNA. J. Biol. Chem. 279, 37822-37831. doi: 10.1074/jbc.M314203200

Sanz, M. A., Welnowska, E., Redondo, N., and Carrasco, L. (2010). Translation driven by picornavirus IRES is hampered from Sindbis virus replicons: rescue 
by poliovirus 2A protease. J. Mol. Biol. 402, 101-117. doi: 10.1016/j.jmb.2010. 07.014

Sasaki, J., Ishikawa, K., and Taniguchi, K. (2012). 3CD, but not 3C, cleaves the VP1/2A site efficiently during Aichi virus polyprotein processing through interaction with 2A. Virus Res. 163, 592-598. doi: 10.1016/j.virusres.2011.12.013

Sasaki, J., and Taniguchi, K. (2008). Aichi virus 2A protein is involved in viral RNA replication. J. Virol. 82, 9765-9769. doi: 10.1128/jvi.01051-08

Singh, M., Lee, S. H., Porter, P., Xu, C., Ohno, A., Atmar, R. L., et al. (2010). Human rhinovirus proteinase $2 \mathrm{~A}$ induces $\mathrm{TH} 1$ and $\mathrm{TH} 2$ immunity in patients with chronic obstructive pulmonary disease. J. Allergy Clin. Immunol. 125, 1369.e2-1378.e2. doi: 10.1016/j.jaci.2010.02.035

Song, Q. Q., Lu, M. Z., Song, J., Chi, M. M., Sheng, L. J., Yu, J., et al. (2015). Coxsackievirus B3 2A protease promotes encephalomyocarditis virus replication. Virus Res. 208, 22-29. doi: 10.1016/j.virusres.2015.05.020

Sousa, C., Schmid, E. M., and Skern, T. (2006). Defining residues involved in human rhinovirus $2 \mathrm{~A}$ proteinase substrate recognition. FEBS Lett. 580, 5713-5717. doi: 10.1016/j.febslet.2006.09.023

Sun, D., Chen, S., Cheng, A., and Wang, M. (2016). Roles of the picornaviral $3 \mathrm{C}$ proteinase in the viral life cycle and host cells. Viruses 8:82. doi: 10.3390/ v8030082

Sun, Y., Wang, X., Yuan, S., Dang, M., Li, X., Zhang, X. C., et al. (2013). An open conformation determined by a structural switch for $2 \mathrm{~A}$ protease from coxsackievirus A16. Protein Cell 4, 782-792. doi: 10.1007/s13238-013-3914-Z

Sun, Y. F., Lin, Y., Zhang, J. H., Zheng, S. P., Ye, Y. R., Liang, X. X., et al. (2012). Double Candida antarctica lipase B co-display on Pichia pastoris cell surface based on a self-processing foot-and-mouth disease virus 2A peptide. Appl. Microbiol. Biotechnol. 96, 1539-1550. doi: 10.1007/s00253-012-4264-0

Tan, H. X., Gilbertson, B. P., Jegaskanda, S., Alcantara, S., Amarasena, T., Stambas, J., et al. (2016). Recombinant influenza virus expressing HIV-1 p24 capsid protein induces mucosal HIV-specific CD8 T-cell responses. Vaccine 34, 1172-1179. doi: 10.1016/j.vaccine.2016.01.030

Tang, X., Liu, X., Tao, G., Qin, M., Yin, G., Suo, J., et al. (2016). "Self-cleaving” 2A peptide from porcine teschovirus-1 mediates cleavage of dual fluorescent proteins in transgenic Eimeria tenella. Vet. Res. 47:68. doi: 10.1186/s13567-0160351-z

Teterina, N. L., Levenson, E. A., and Ehrenfeld, E. (2010). Viable polioviruses that encode 2 A proteins with fluorescent protein tags. J. Virol. 84, 1477-1488. doi: 10.1128/jvi.01578-09

Tian, W., Cui, Z., Zhang, Z., Wei, H., and Zhang, X. (2011). Poliovirus 2Apro induces the nucleic translocation of poliovirus $3 \mathrm{CD}$ and $3 \mathrm{C}^{\prime}$ proteins. Acta Biochim. Biophys. Sin. 43, 38-44. doi: 10.1093/abbs/gmq112

Tsai, F. M., Shyu, R. Y., Lin, S. C., Wu, C. C., and Jiang, S. Y. (2009). Induction of apoptosis by the retinoid inducible growth regulator RIG1 depends on the NC motif in HtTA cervical cancer cells. BMC Cell Biol. 10:15. doi: 10.1186/14712121-10-15

Tseng, C. H., Knowles, N. J., and Tsai, H. J. (2007). Molecular analysis of duck hepatitis virus type 1 indicates that it should be assigned to a new genus. Virus Res. 123, 190-203. doi: 10.1016/j.virusres.2006.09.007

Tseng, C. H., and Tsai, H. J. (2007a). Molecular characterization of a new serotype of duck hepatitis virus. Virus Res. 126, 19-31. doi: 10.1016/j.virusres.2007.01.012

Tseng, C. H., and Tsai, H. J. (2007b). Sequence analysis of a duck picornavirus isolate indicates that it together with porcine enterovirus type 8 and simian picornavirus type 2 should be assigned to a new picornavirus genus. Virus Res. 129, 104-114. doi: 10.1016/j.virusres.2007.06.023

Wang, B., Xi, X., Lei, X., Zhang, X., Cui, S., Wang, J., et al. (2013). Enterovirus 71 protease 2Apro targets MAVS to inhibit anti-viral type I interferon responses. PLoS Pathog. 9:e1003231. doi: 10.1371/journal.ppat.1003231

Wang, C. Y., Huang, A. C., Hour, M. J., Huang, S. H., Kung, S. H., Chen, C. H., et al. (2015). Antiviral potential of a novel compound CW-33 against enterovirus A71 via inhibition of viral 2A protease. Viruses 7, 3155-3171. doi: 10.3390/v7062764
Wang, H., Lei, X., Xiao, X., Yang, C., Lu, W., Huang, Z., et al. (2015). Reciprocal regulation between enterovirus 71 and the NLRP3 inflammasome. Cell Rep. 12, 42-48. doi: 10.1016/j.celrep.2015.05.047

Wang, L. C., Chen, S. O., Chang, S. P., Lee, Y. P., Yu, C. K., Chen, C. L., et al. (2015). Enterovirus 71 proteins $2 \mathrm{~A}$ and $3 \mathrm{D}$ antagonize the antiviral activity of gamma interferon via signaling attenuation. J. Virol. 89, 7028-7037. doi: 10.1128/jvi.00205-15

Wang, Q. M. (2001). Protease inhibitors as potential antiviral agents for the treatment of picornaviral infections. Prog. Drug Res. 52, 197-219. doi: 10.1007/ 978-3-0348-8730-4_5

Wang, S., Yao, Q., Tao, J., Qiao, Y., and Zhang, Z. (2007). Co-ordinate expression of glycine betaine synthesis genes linked by the FMDV 2A region in a single open reading frame in Pichia pastoris. Appl. Microbiol. Biotechnol. 77, 891-899. doi: 10.1007/s00253-007-1222-3

Wang, X., Liu, N., Wang, F., Ning, K., Li, Y., and Zhang, D. (2014). Genetic characterization of a novel duck-origin picornavirus with six $2 \mathrm{~A}$ proteins. J. Gen. Virol. 95, 1289-1296. doi: 10.1099/vir.0.063313-0

Watters, K., and Palmenberg, A. C. (2011). Differential processing of nuclear pore complex proteins by rhinovirus $2 \mathrm{~A}$ proteases from different species and serotypes. J. Virol. 85, 10874-10883. doi: 10.1128/jvi.00718-11

Wei, H., Wang, L., Ren, X., Yu, W., Lin, J., Jin, C., et al. (2015). Structural and functional characterization of tumor suppressors TIG3 and H-REV107. FEBS Lett. 589, 1179-1186. doi: 10.1016/j.febslet.2015.04.002

Wong, J., Zhang, J., Yanagawa, B., Luo, Z., Yang, X., Chang, J., et al. (2012). Cleavage of serum response factor mediated by enteroviral protease $2 \mathrm{~A}$ contributes to impaired cardiac function. Cell Res. 22, 360-371. doi: 10.1038/cr.2011.114

Wu, S., Wang, Y., Lin, L., Si, X., Wang, T., Zhong, X., et al. (2014). Protease 2A induces stress granule formation during coxsackievirus B3 and enterovirus 71 infections. Virol. J. 11:192. doi: 10.1186/s12985-014-0192-1

Xiong, D., Yajima, T., Lim, B. K., Stenbit, A., Dublin, A., Dalton, N. D., et al. (2007). Inducible cardiac-restricted expression of enteroviral protease $2 \mathrm{~A}$ is sufficient to induce dilated cardiomyopathy. Circulation 115, 94-102. doi: 10. 1161/circulationaha.106.631093

Yang, C. H., Li, H. C., Jiang, J. G., Hsu, C. F., Wang, Y. J., Lai, M. J., et al. (2010). Enterovirus type $712 \mathrm{~A}$ protease functions as a transcriptional activator in yeast. J. Biomed. Sci. 17:65. doi: 10.1186/1423-0127-17-65

Yen, H. H., and Scheerlinck, J. P. (2013). Biological activity of ovine IL-23 expressed using a foot-and-mouth disease virus $2 \mathrm{~A}$ self-cleaving peptide. Cytokine 61, 744-746. doi: 10.1016/j.cyto.2013.01.014

Yu, S. F., and Lloyd, R. E. (1992). Characterization of the roles of conserved cysteine and histidine residues in poliovirus $2 \mathrm{~A}$ protease. Virology 186, 725-735. doi: 10.1016/0042-6822(92)90039-R

Zeng, J., Chen, X., Dai, J., Zhao, X., Xin, G., Su, Y., et al. (2013). An attenuated coxsackievirus b3 vector: a potential tool for viral tracking study and gene delivery. PLoS ONE 8:e83753. doi: 10.1371/journal.pone.0083753

Zhao, T., Huang, X., and Xia, Y. (2016). Human heart cell proteins interacting with a C-terminally truncated $2 \mathrm{~A}$ protein of coxsackie B3 virus: identification by the yeast two-hybrid system. Virus Genes 52, 172-178. doi: 10.1007/s11262$015-127$

Conflict of Interest Statement: The authors declare that the research was conducted in the absence of any commercial or financial relationships that could be construed as a potential conflict of interest.

Copyright (c) 2017 Yang, Cheng, Wang, Jia, Sun, Pan, Yang, Wu, Zhu, Chen, Liu, Zhao and Chen. This is an open-access article distributed under the terms of the Creative Commons Attribution License (CC BY). The use, distribution or reproduction in other forums is permitted, provided the original author(s) or licensor are credited and that the original publication in this journal is cited, in accordance with accepted academic practice. No use, distribution or reproduction is permitted which does not comply with these terms. 